Article

\title{
Periodic Mesoporous Organosilica Nanoparticles with BOC Group, towards HIFU Responsive Agents
}

\author{
Hao Li ${ }^{1,2}$, Carolina Gascó ${ }^{2}$, Anthony Delalande ${ }^{3}$, Clarence Charnay ${ }^{1} \mathbb{1}$, Laurence Raehm ${ }^{1}$, \\ Patrick Midoux ${ }^{3}$, Chantal Pichon ${ }^{3}$, Roser Pleixats ${ }^{2, *}$ and Jean-Olivier Durand ${ }^{1, *(D)}$ \\ 1 ICGM, Univ Montpellier, CNRS, case 1701, Place Eugène Bataillon, CEDEX 05, 34095 Montpellier, France; \\ Hao.Li@uab.cat (H.L.); clarence.charnay@umontpellier.fr (C.C.); laurence.raehm@umontpellier.fr (L.R.) \\ 2 Departament de Química and Centro de Innovación en Química Avanzada (ORFEO-CINQA), \\ Facultat de Ciències, Universitat Autònoma de Barcelona, UAB Campus, C/dels Til.lers, \\ 08193 Cerdanyola del Vallès (Barcelona), Spain; Carolina.Gasco@uab.cat \\ 3 Center for Molecular Biophysics, (CBM, UPR 4301), Rue Charles Sadron, 45071 Orléans, France; \\ anthony.delalande@cnrs-orleans.fr (A.D.); patrick.midoux@cnrs-orleans.fr (P.M.); \\ chantal.pichon@cnrs-orleans.fr (C.P.) \\ * Correspondence: roser.pleixats@uab.cat (R.P.); jean-olivier.durand@umontpellier.fr (J.O.-D.); \\ Tel.: +33-4-67-14-45-01 (J.O.-D.)
}

Academic Editors: Ahmad Mehdi and Sébastien Clément Received: 29 January 2020; Accepted: 20 February 2020; Published: 21 February 2020

\begin{abstract}
Periodic Mesoporous Organosilica Nanoparticles (PMONPs) are nanoparticles of high interest for nanomedicine applications. These nanoparticles are not composed of silica $\left(\mathrm{SiO}_{2}\right)$. They belong to hybrid organic-inorganic systems. We considered using these nanoparticles for $\mathrm{CO}_{2}$ release as a contrast agent for High Intensity Focused Ultrasounds (HIFU). Three molecules (P1-P3) possessing two to four triethoxysilyl groups were synthesized through click chemistry. These molecules possess a tert-butoxycarbonyl (BOC) group whose cleavage in water at $90-100{ }^{\circ} \mathrm{C}$ releases $\mathrm{CO}_{2}$. Bis(triethoxysilyl)ethylene $\mathrm{E}$ was mixed with the molecules Pn (or not for P3) at a proportion of 90/10 to 75/25, and the polymerization triggered by the sol-gel procedure led to PMONPs. PMONPs were characterized by different techniques, and nanorods of 200-300 nm were obtained. These nanorods were porous at a proportion of 90/10, but non-porous at 75/25. Alternatively, molecules $\mathbf{P 3}$ alone led to mesoporous nanoparticles of $100 \mathrm{~nm}$ diameter. The BOC group was stable, but it was cleaved at $\mathrm{pH} 1$ in boiling water. Molecules possessing a BOC group were successfully used for the preparation of nanoparticles for $\mathrm{CO}_{2}$ release. The $\mathrm{BOC}$ group was stable and we did not observe release of $\mathrm{CO}_{2}$ under HIFU at lysosomal $\mathrm{pH}$ of 5.5. The $\mathrm{pH}$ needed to be adjusted to 1 in boiling water to cleave the BOC group. Nevertheless, the concept is interesting for HIFU theranostic agents.
\end{abstract}

Keywords: $\mathrm{HIFU}$; periodic mesoporous organosilica nanoparticles; cancer; $\mathrm{CO}_{2}$

\section{Introduction}

The use of Periodic Mesoporous Organosilica Nanoparticles (PMONPs) has grown a lot in the last decade, particularly for biological applications, and the field has been recently reviewed [1-3]. Hollow Mesoporous Organosilica Nanoparticles have been more recently described and reviewed as well [4]. PMONPs are synthesized from trialkoxypolysilylated organic precursors and usually silica sources are not used for their preparation. PMONPs possess improved properties compared to Mesoporous Silica Nanoparticles (MSN), which have been considerably reported for their nanomedicine applications [5-12]. Indeed, PMONPs can be loaded with hydrophobic or hydrophilic molecules and present better hemolytic properties than MSN $[13,14]$. PMONPs are more stable than MSN in medical relevant conditions [15], but, with disulfide bridges in their structure, their degradability can be triggered by glutathione [16]. 
Functionalized MSN [17,18] and PMONPs [19-22] were combined with high-intensity focused ultrasound (HIFU) for theranostic applications of cancer. Indeed, HIFU has been used for the ablation of pathological lesions and tumors $[23,24]$. Bubbles are usually the most developed contrast agent for HIFU [25-27]. Furthermore, recent efforts have been dedicated to the preparation of carriers able to generate $\mathrm{CO}_{2}$ bubbles [28]. In the course of our studies on PMONPs, we were interested in nanomaterials possessing the tert-butoxycarbonyl (BOC) group. Indeed, BOC, as an amine protective group, can be quickly removed in water at $90-100{ }^{\circ} \mathrm{C}$, generating $\mathrm{CO}_{2}[29,30]$. As $\mathrm{HIFU}$ can heat up to $70-80{ }^{\circ} \mathrm{C}[31,32]$, we thought of synthesizing PMONPs from polytrialkoxysilylated BOC-functionalized molecules in order to develop PMONP-based contrast agents for HIFU.

We present here our studies of the syntheses of three bis(triethoxysilylated) P1 and tetra(triethoxysilylated) molecules P2, P3 (Scheme 1) possessing a BOC group, and their reaction through the sol-gel procedure with bis(triethoxysilyl)ethylene E. The materials called E-Pn 90/10 PMONPs or E-Pn 75/25 PMONPs correspond to a sol-gel reaction with 90\% molecule E and 10\% molecule Pn, or 75\% molecule E and 25\% molecule Pn, respectively. E PMONPs was also synthesized and corresponds to $100 \%$ of molecule E. The materials were analyzed with different techniques and showed mesoporosity at a 10\% proportion of P1-P3 molecules. When the proportion increased, no more porosity was observed. Pure P3 PMONPs with the tetra(triethoxysilylated) molecule P3 are also described and showed mesopores of $5.6 \mathrm{~nm}$. PMONPs are, therefore, promising materials for theranostic applications.
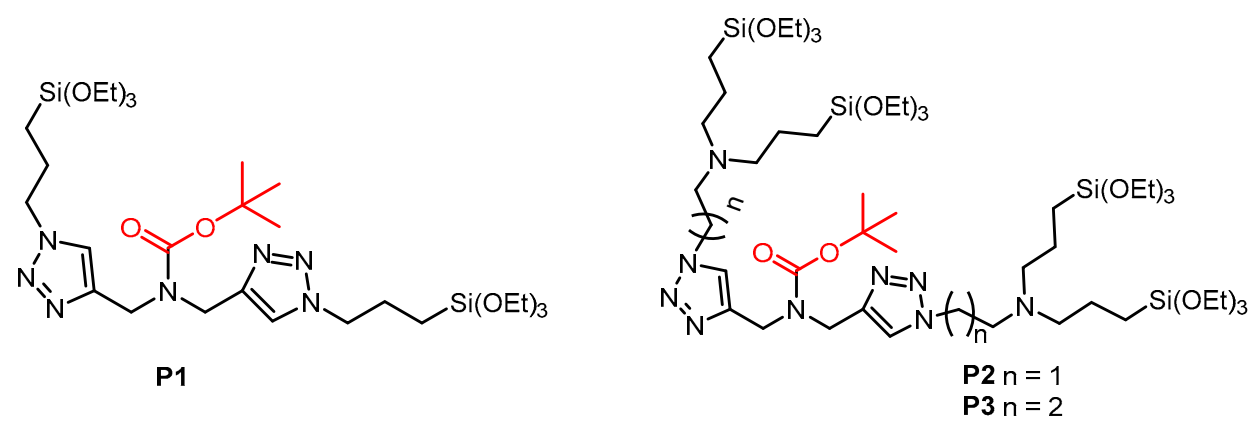

Scheme 1. Proposed bis(triethoxysilylated) and tetra(triethoxysilylated) molecules P1-P3 for the preparation of PMONPs.

\section{Results and Discussion}

We envisaged to synthesize the bis(triethoxysilylated) and tetra(triethoxysilylated) molecules P1-P3 possessing a BOC group through a copper-catalyzed azide-alkyne cycloaddition reaction (CuAAC) under anhydrous conditions [33], by treatment of the appropriate dialkyne with 3-azidopropyltriethoxysilane, 3-azido- $N, N$-bis(triethoxysilylpropyl)propanamine or 2-azido- $N, N$-bis(triethoxysilylpropyl)ethanamine [34], respectively (Scheme 1).

$N$-Boc protection of propargyl amine 1 furnished carbamate 2 in $91 \%$ yield, which was reacted with propargyl bromide in the presence of $\mathrm{NaH}$ in anhydrous THF to afford dialkyne 3 in quantitative yield (Scheme 2) [35].

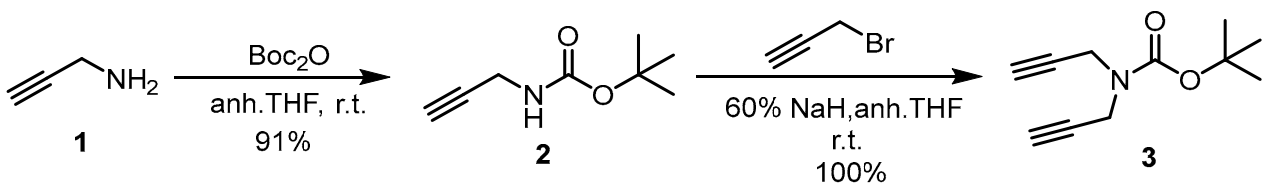

Scheme 2. Synthesis of tert-butyl di(prop-2-yn-1-yl)carbamate.

The bis-silylated precursor $\mathbf{P 1}$ was obtained by the reaction of dialkyne 3 with (3-azidopropyl)triethoxysilane under copper (I) catalysis under anhydrous conditions. First, the copper 
catalyst $\left[\mathrm{CuBr}\left(\mathrm{PPh}_{3}\right)_{3}\right]$ was used, but we found that it was difficult to remove it from the crude mixture by washing with different solvents after the reaction. Then, $\mathrm{CuI}$ was chosen as a copper source and tris[(1-benzyl-1H-1,2,3-triazol-4-yl)methyl]amine (TBTA) as a ligand that stabilizes $\mathrm{Cu}(\mathrm{I})$ ions in a 1:1 mixture of anhydrous $\mathrm{Et}_{3} \mathrm{~N} /$ anhydrous $\mathrm{THF}$ at $50^{\circ} \mathrm{C}$ overnight (Scheme 3). After the work-up and purification, the bis(silylated) precursor P1 was obtained at 73\% yield. The purification was performed by washing with hot anhydrous pentane several times. As the product remains partially dissolved in pentane, the isolated yield is lower.

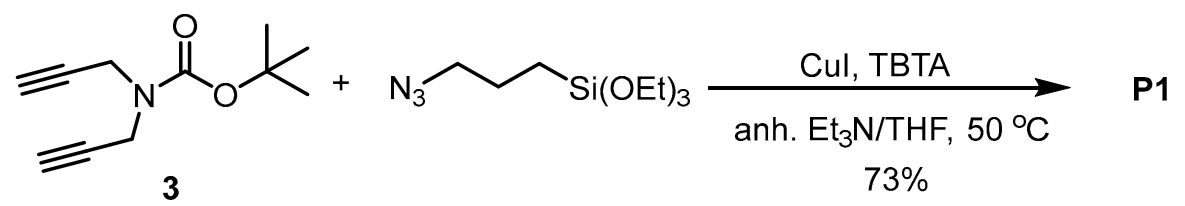

Scheme 3. Synthesis of bis(silylated) precursor P1.

Similarly, the other two silylated precursors P2 and P3 were obtained, both at 96\% yield, by reacting the corresponding bis(silylated azide) with dialkyne 3 under the same reaction conditions (Scheme 4).

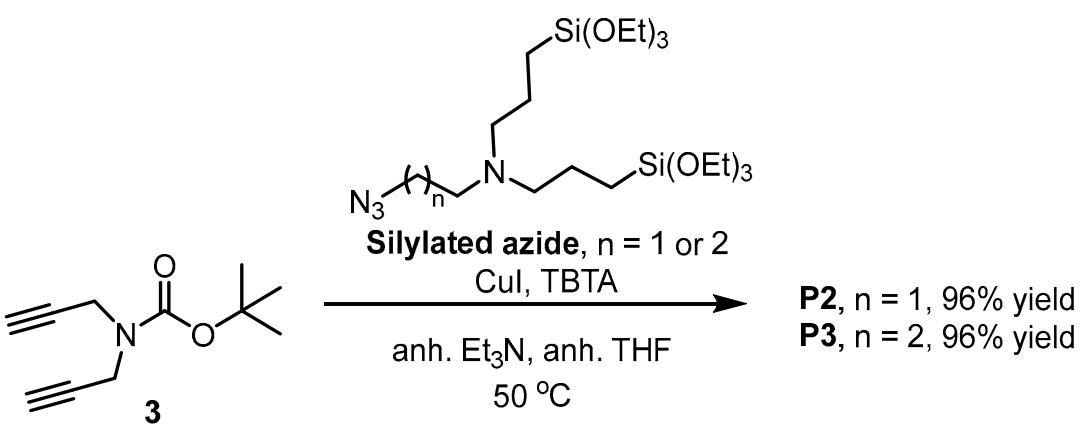

Scheme 4. Synthesis of silylated precursors P2 and P3.

With those precursors in hands, we next performed the sol-gel procedure in highly diluted conditions with 1,2-bis(triethoxysilyl)ethene (E) as the major reagent. First, the synthesis was performed in Mili-Q water with cetyltrimethylammonium bromide (CTAB) micellar template and sodium hydroxide catalysis at $80{ }^{\circ} \mathrm{C}$. The template was prepared at this temperature for $50 \mathrm{~min}$ with a stirring speed adjusted at $1400 \mathrm{rpm}$. Then, 1,2-bis(triethoxysilyl)ethene (in a proportion of 90\% or 75\%) was added with P1-P3 (in a proportion of $10 \%$ or $25 \%$ ) and the mixture reacted for two hours. Nanoparticles were collected by centrifugation and the template was removed by washing with an ethanolic solution of ammonium nitrate; the resulting material was washed successively with ethanol, Mili-Q water and ethanol. Herein, two different ratios of E-Pn were tested-90/10, 75/25-in order to study their influence on the NPs' size and morphology.

All the mixed periodic mesoporous organosilica nanoparticles were characterized by TEM, nitrogen-sorption measurements (BET), p-XRD, FTIR, ${ }^{13} \mathrm{C}-\mathrm{CP}$ MAS solid-state NMR, DLS, zeta-potential, TGA and DSC. Some physical data are given in Table 1. 
Table 1. Some physical data of E-Pn PMONPs and P3 PMONPs.

\begin{tabular}{|c|c|c|c|c|c|c|c|}
\hline \multirow[b]{2}{*}{ Material } & \multicolumn{3}{|c|}{$\mathrm{N}_{2}$-Sorption Measurements } & \multirow{2}{*}{$\begin{array}{c}\text { Particles } \\
{\text { Size }(n m)^{c}}^{c}\end{array}$} & \multicolumn{2}{|c|}{ Zêta Potential } & \multirow[b]{2}{*}{ TGA $^{\mathrm{d}}$} \\
\hline & $\begin{array}{c}S_{\mathrm{BET}} \\
\left(\mathrm{m}^{2} \cdot \mathrm{g}^{-1}\right)\end{array}$ & $\begin{array}{c}V_{\text {pore }} \\
\left(\mathrm{cm}^{3} \cdot \mathrm{g}^{-1}\right)^{\mathrm{a}}\end{array}$ & $\emptyset_{\text {pore }}(\mathrm{nm})^{b}$ & & $\mathrm{pH}$ & $(\mathrm{mV})$ & \\
\hline E-P1 90/10 PMONPs & 683 & 0.48 & 2.8 & 447 & 6.96 & -28 & $78 \%$ \\
\hline E-P2 90/10 PMONPs & 509 & 0.34 & 2.7 & 800 & 5.92 & 32 & $75 \%$ \\
\hline E-P3 90/10 PMONPs & 505 & 0.36 & 2.8 & 479 & 5.44 & 36 & $72 \%$ \\
\hline E-P1 75/25 PMONPs & low & nd & nd & 507 & 7.34 & -22 & $67 \%$ \\
\hline E-P2 75/25 PMONPs & low & nd & nd & 513 & 6.25 & 20 & $58 \%$ \\
\hline E-P3 75/25 PMONPs & low & nd & nd & 321 & 4.86 & 24 & $57 \%$ \\
\hline P3 PMONPs & 186 & 0.26 & 5.6 & 269 & 8.94 & 11 & nd $\mathrm{e}^{\mathrm{a}}$ \\
\hline
\end{tabular}

${ }^{a}$ Determined from the uptake at saturation at $\mathrm{p} / \mathrm{p}^{\circ}=0.98 .{ }^{\mathrm{b}}$ Diameter determined by BJH. ${ }^{\mathrm{c}}$ Hydrodynamic diameters from DLS. ${ }^{\mathrm{d}}$ Residual mass, TGA with a heating rate of $10^{\circ} \mathrm{C} / \mathrm{min}$ from 30 to $1000^{\circ} \mathrm{C}$. ${ }^{\mathrm{e}}$ Not determined.

The morphologies of E-Pn were first analyzed by TEM (Figure 1), and for the majority of the materials rodlike-shape nanoparticles were obtained ranging from $200 \mathrm{~nm}$ for (E-P1, E-P3 90/10) to $300 \mathrm{~nm}$ long for E-P2. For E-P3 75/25, nanoparticles of $150 \mathrm{~nm}$ were observed. The hydrodynamic diameters of the nanorods were investigated by DLS, (Table 1) and the obtained diameters were in agreement with the sizes determined by TEM. E-P2 showed higher hydrodynamic diameters than E-P1 and E-P3. The hydrodynamic diameter of E-P3 75/25 was lower than (E-P1, E-P2, E-P3 90/10) in agreement with a smaller size and particle morphology compared to nanorods. The zeta potentials were determined in water (Table 1). E-P1 showed negative zeta potential, in agreement with the presence of $\mathrm{Si}_{-} \mathrm{O}^{-}$at the surface of the nanorods. The zeta potential of E-P2 and E-P3 was positive because the amino groups of $\mathbf{P} \mathbf{2}$ and $\mathbf{P} 3$ were protonated below $\mathrm{pH} 7$.

$90 / 10$
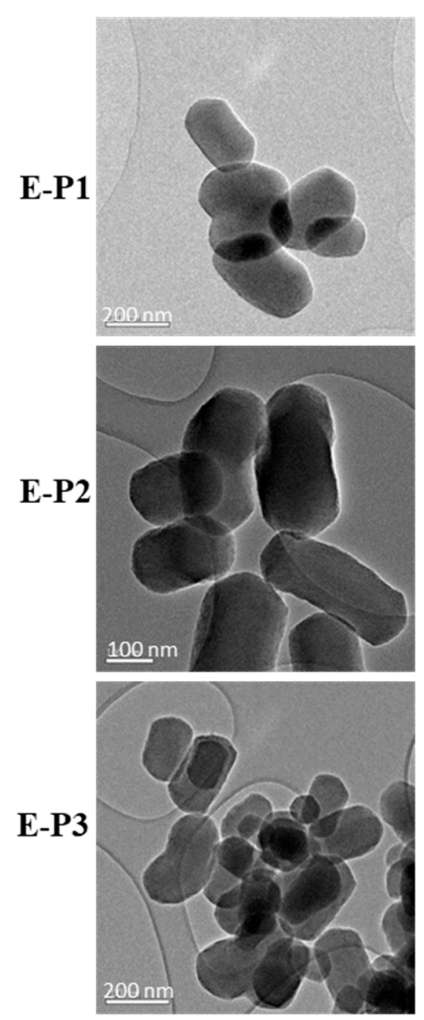
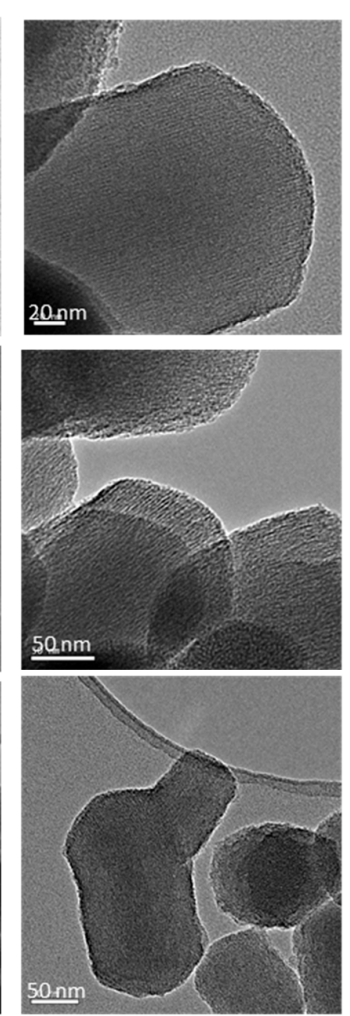
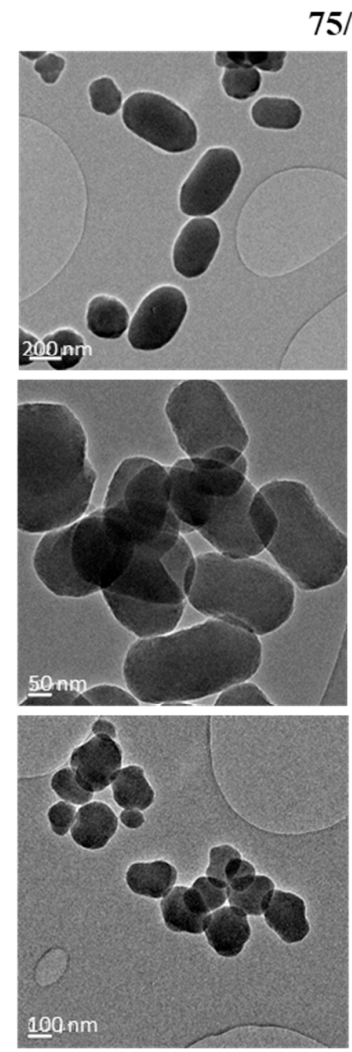

$75 / 25$
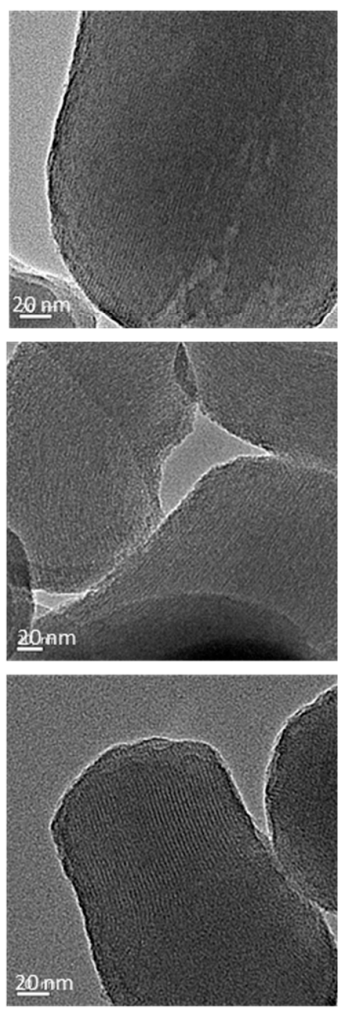

Figure 1. TEM images of PMONPs (E-P1; E-P2; E-P3, proportion 90/10 and 75/25). 
The $\mathrm{N}_{2}$ adsorption-desorption isotherms were next examined (Figure 2). All the materials showed an isotherm between type I and type IV, and between microporous and mesoporous systems. Nanorods from E (already synthesized) [36] showed a very high specific surface area of $800 \mathrm{~m}^{2} \cdot \mathrm{g}^{-1}$ with an average small pore size of $2.5 \mathrm{~nm}$. When incorporating P1, E-P1 90/10 showed a decrease in specific surface area to $683 \mathrm{~m}^{2} \cdot \mathrm{g}^{-1}$ and a small increase in pore size to $2.8 \mathrm{~nm}$. The incorporation of $\mathbf{P 2}$ and $\mathbf{P 3}$ at a proportion of 90/10 led to a decrease in specific surface area to $500 \mathrm{~m}^{2} \cdot \mathrm{g}^{-1}$ with an increase of pore size to 2.7 and $2.8 \mathrm{~nm}$, respectively. Note that when increasing the proportion of precursors P1-3 to 75/25, materials E-P1-3, showed no adsorption of $\mathrm{N}_{2}$ any more at $78 \mathrm{~K}$, which suggests that the porosity is not accessible to $\mathrm{N}_{2}$ at this temperature.

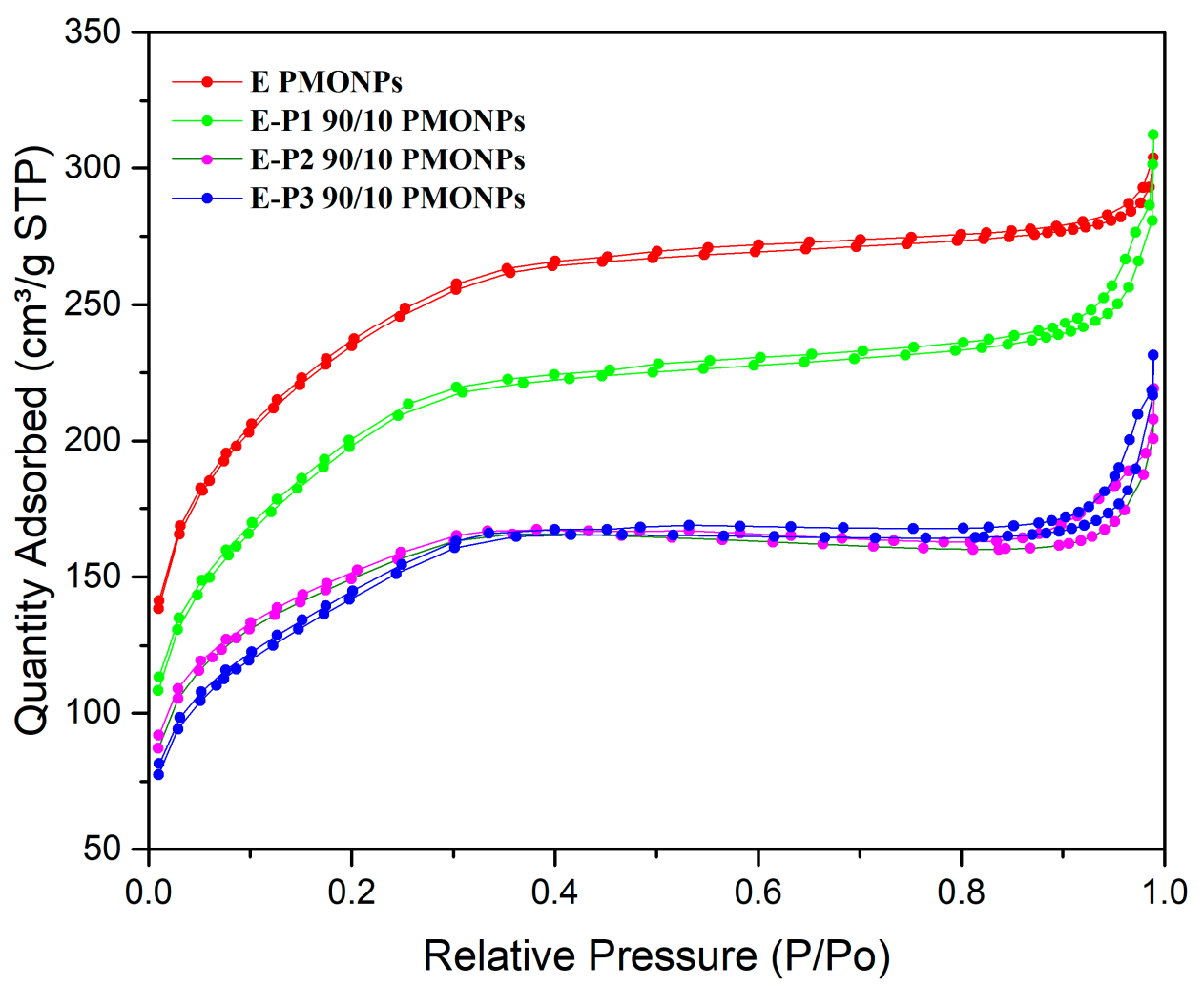

Figure 2. $\mathrm{N}_{2}$ adsorption-desorption experiments (BET) of E, E-P1, E-P2, E-P3, at a proportion of 90/10.

Small Angle X-rays diffraction of nanorods from $\mathbf{E}[36]$ (Figure 3) showed the $\mathrm{d}(1,0,0)$ Bragg peak at $2.2 \theta$, with the satellites at $\mathrm{d}(1,1,0) 4.0 \theta$ and $\mathrm{d}(2,0,0) 4.6 \theta$, characteristics of a well-ordered hexagonal mesoporosity. The other materials are more disordered with a wormlike mesoporosity and a broad non-structured band (see XRD of E-P1 90/10 and E-P1 75/25 as representative examples).

FTIR were recorded for all the precursors and materials. A representative example is given in Figure 4 with P2, E-P2 90/10 and E-P2 75/25. P2 showed the presence of the BOC group at $2973 \mathrm{~cm}^{-1}\left(\mathrm{vCH}_{3}\right)$, the carbon chains at 2927 and $2883 \mathrm{~cm}^{-1}\left(\mathrm{vCH}_{2}\right)$, the carbonyl of the carbamate at $1696 \mathrm{~cm}^{-1}(v \mathrm{C}=\mathrm{O})$, the triazole $v \mathrm{CH}$ at $1457-1386 \mathrm{~cm}^{-1}$, the silicon-oxygen bonds at $1073 \mathrm{~cm}^{-1}$ ( $v \mathrm{Si}-\mathrm{O})$. All the bands were essentially the same in the materials, with a shift in the carbonyl to $1675-1672 \mathrm{~cm}^{-1}$ showing a different environment of the BOC group in the material. A broad band between $1200-1000 \mathrm{~cm}^{-1}$ (( $\left.\mathrm{VSi}-\mathrm{O}-\mathrm{Si}\right)$, characteristic of a well-condensed material, was observed.

${ }^{13}$ C-CPMAS solid-state, NMR were also recorded. Spectrum (E-P2 75/25) is representative (Figure 5) and showed the characteristic signals (in ppm) at $155.9(\mathrm{C}=\mathrm{O}), 145.3(\mathrm{C}=\mathrm{C}, \mathrm{Cq}$ triazole), 124.0 (CH triazole), $80.4(\mathrm{Cq}, t \mathrm{Bu}), 55.2\left(\mathrm{CH}_{2}-\mathrm{N}, \mathrm{CH}_{2}\right.$-triazole $), 28.6\left(\mathrm{CH}_{3} \mathrm{Bu}\right)$ 21.6(- $\left.\mathrm{CH}_{2}-\right), 11.2\left(\mathrm{CH}_{2}-\mathrm{Si}\right)$. 


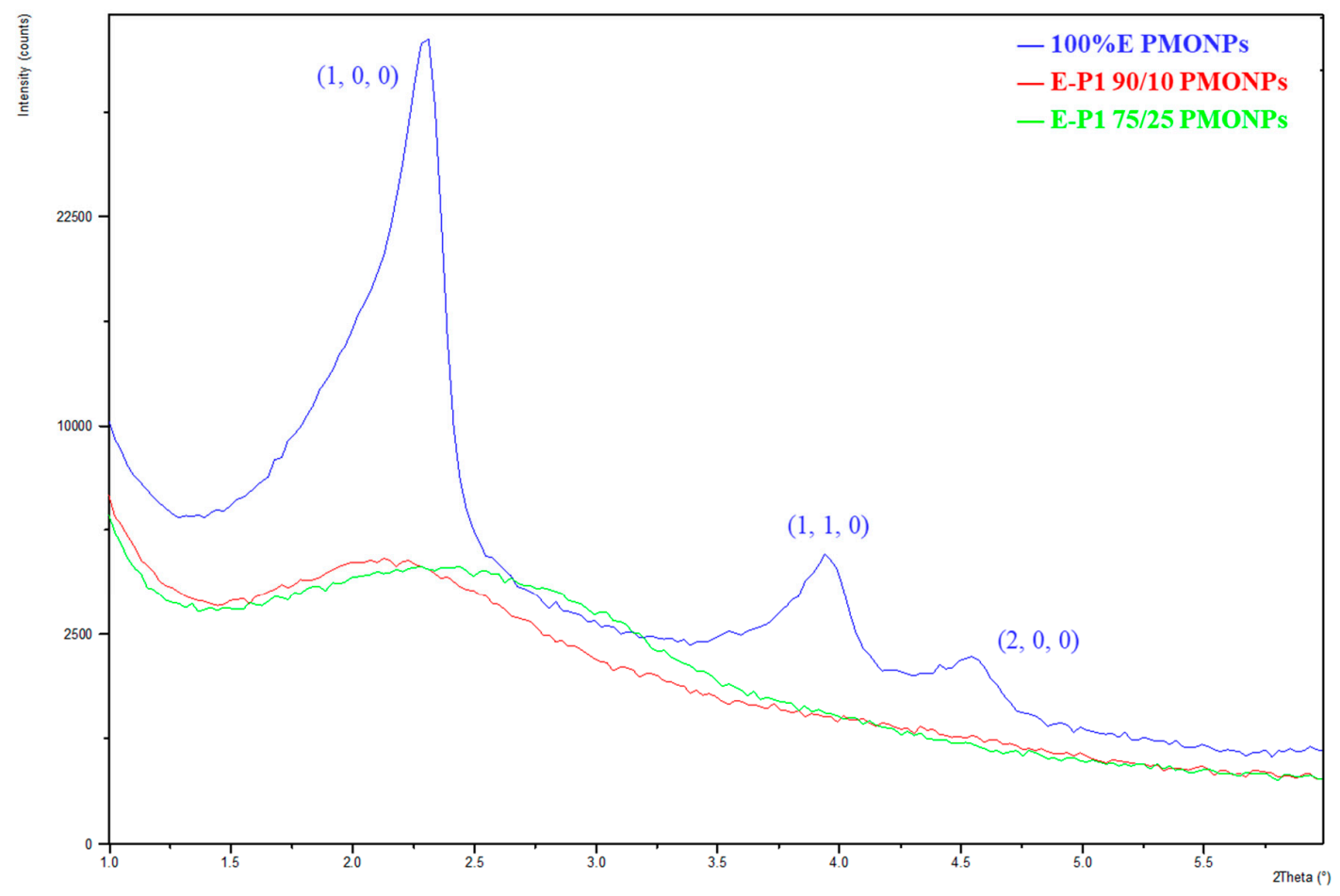

Figure 3. Small angle XRD diagram of E (blue line), E-P1 90/10 (red line), E-P1 75/25 (green line).

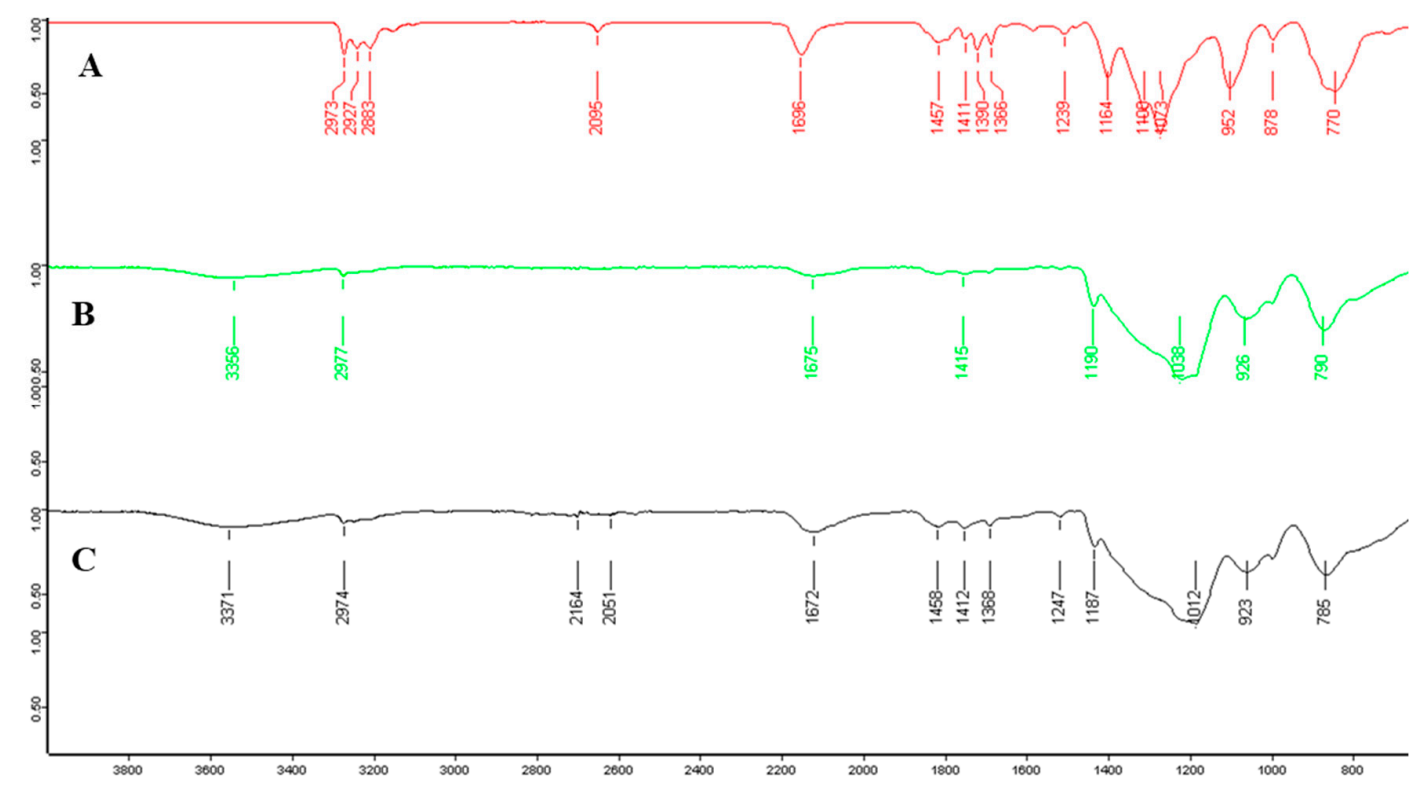

Figure 4. FTIR of (A) P2, (B) E-P2 90/10 and (C) E-P2 75/25.

TGA analyses were performed (Figure 6). The first loss of mass corresponded to water (up to $120^{\circ} \mathrm{C}$ ). From 150 to $220^{\circ} \mathrm{C}$, the loss of the BOC group was observed. The BOC group was very stable in the materials in dry state, as no loss of mass was observed before $120^{\circ} \mathrm{C}$. Then, the decomposition of the organic part of the materials was shown. 


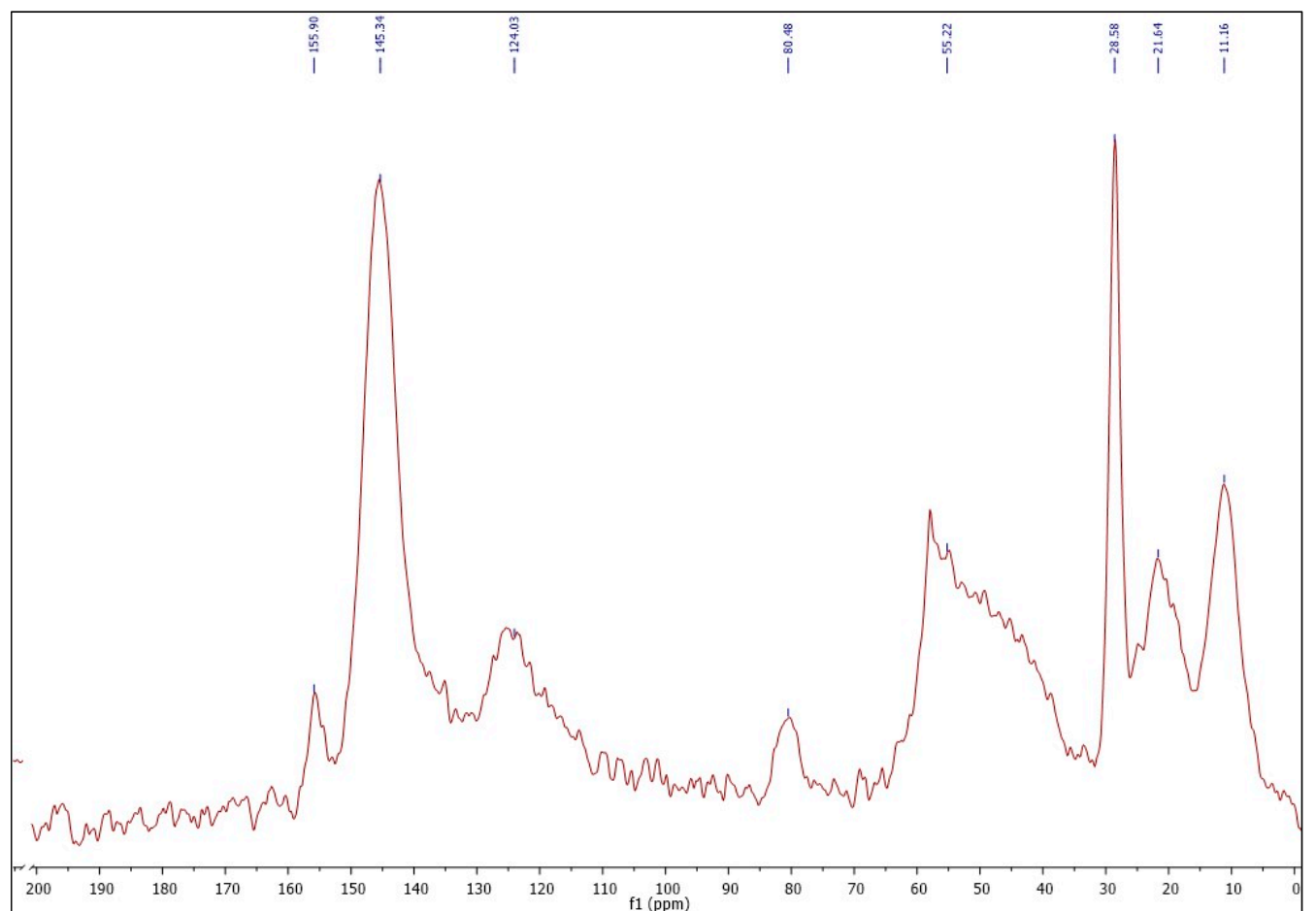

Figure 5. ${ }^{13}$ C-CP-MAS solid-state NMR of E-P2 75/25.

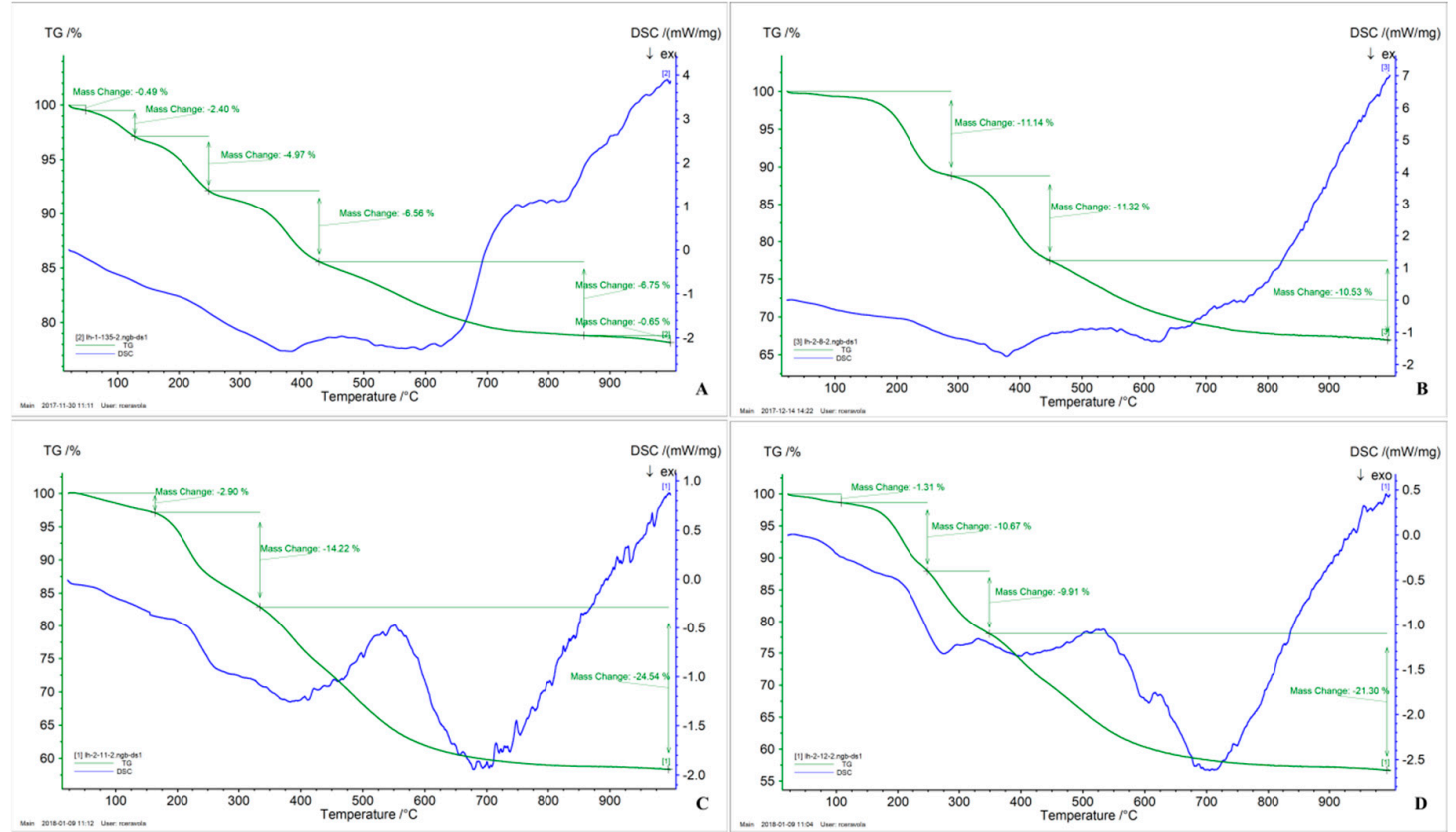

Figure 6. TGA-DSC of (A) E-P1 90/10. (B) E-P1 75/25. (C) E-P2 75/25, (D) E-P3 75/25.

We then performed the synthesis of P3 PMONPs. For this, P3 was used as the only precursor (no silica source). CTAB was dissolved in aqueous $\mathrm{NaOH}$ at $80^{\circ} \mathrm{C}$ in highly diluted conditions for $50 \mathrm{~min}$, then the precursor $\mathbf{P 3}$, dissolved in $\mathrm{EtOH}$, was rapidly added. The condensation mixture was stirred at $80^{\circ} \mathrm{C}$ for $24 \mathrm{~h}$, then extraction of $\mathrm{CTAB}$ and drying of the sample was performed as above. The nanoparticles were analyzed using different techniques.

First, TEM images (Figure 7) showed spherical monodisperse nanoparticles (100 nm diameter) which seem to be composed of sheets of organosilica. The nanoparticles are clearly porous on TEM 
images. The porosity was confirmed with $\mathrm{N}_{2}$ sorption experiments (BET). Indeed, a type IV isotherm was obtained (Figure 8) and the porosity was determined to be $5.6 \mathrm{~nm}$. The hydrodynamic diameter was observed at $269 \mathrm{~nm}$ and zeta potential was positive, in agreement with the protonation of tertiary nitrogen atoms (Table 1). The precursor P3 was not damaged after reaction, as shown by FTIR spectroscopy (Figure 9) with the carbonyl group observed at $1682 \mathrm{~cm}^{-1}$.
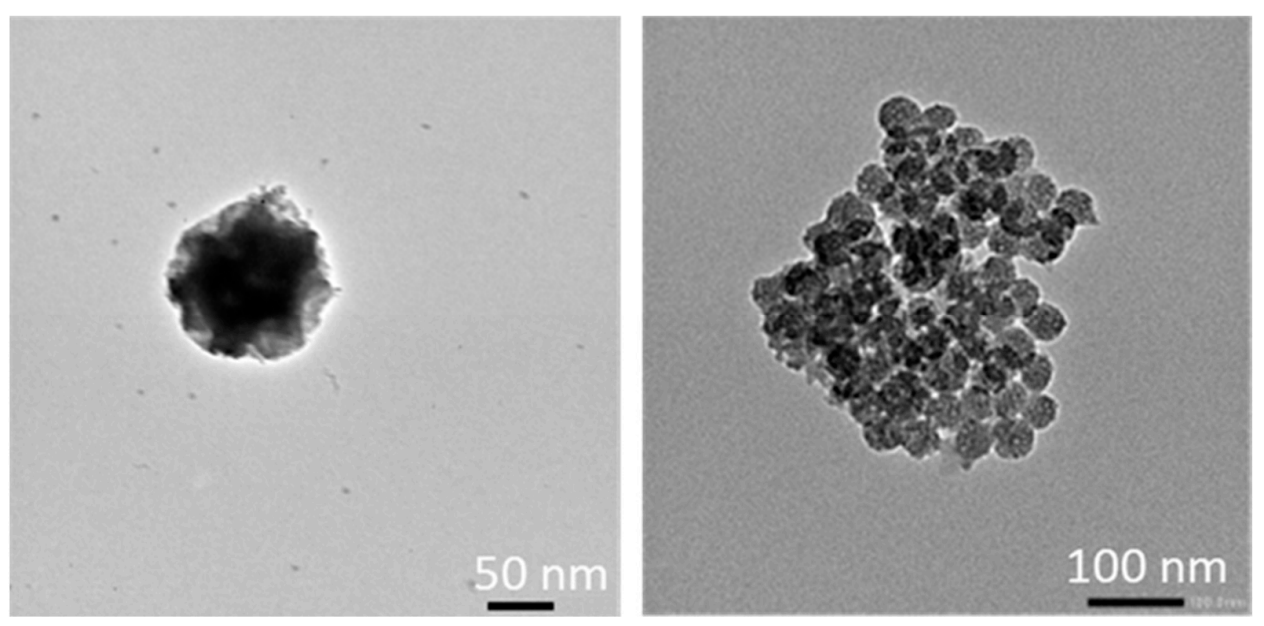

Figure 7. TEM of P3 Periodic Mesoporous Organosilica Nanoparticles (PMONPs) at different magnifications.
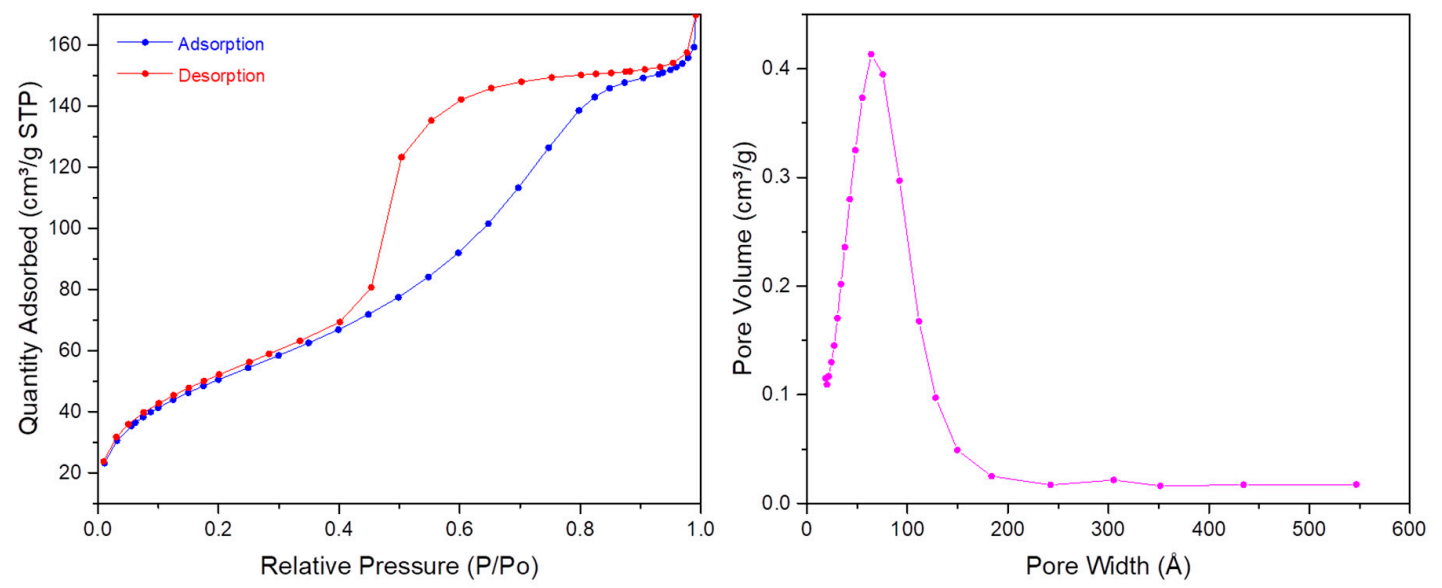

Figure 8. $\mathrm{N}_{2}$ adsorption-desorption experiments (BET) of P3 PMONPs.

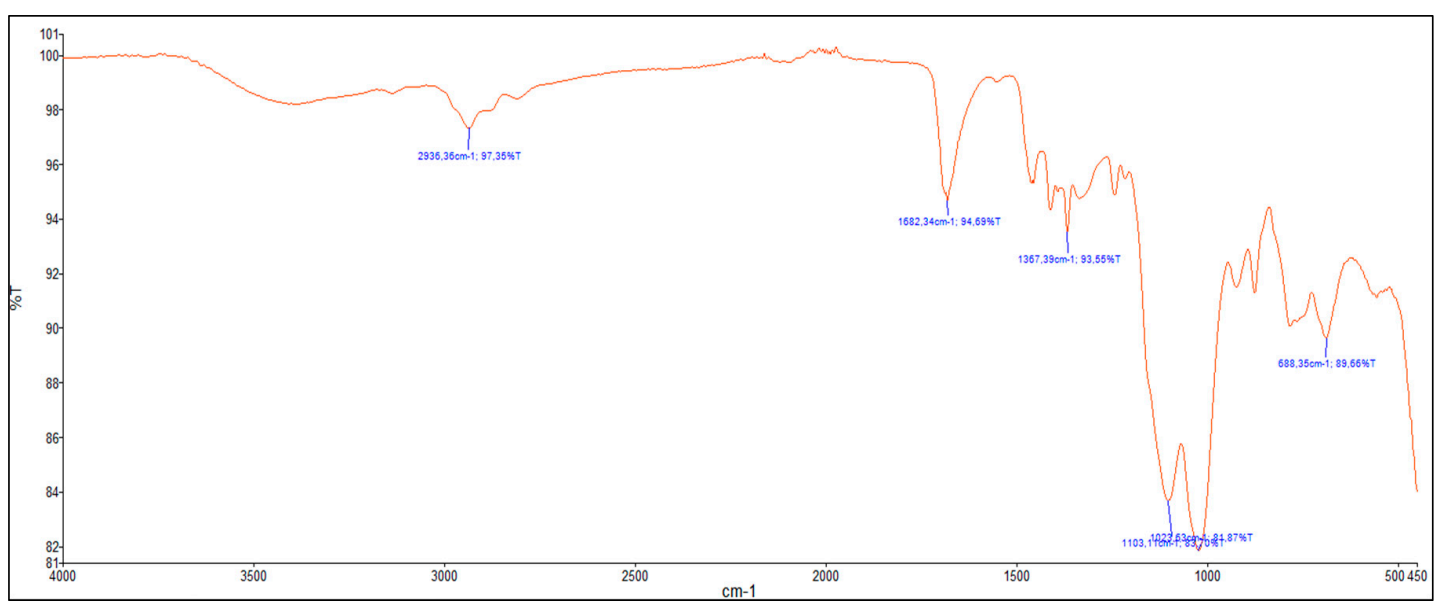

Figure 9. FTIR of P3 PMONPs. 
E-P3 75/25 PMONPs were selected for the release of $\mathrm{CO}_{2}$, first under water conditions at $100{ }^{\circ} \mathrm{C}$. A total of $50 \mathrm{mg}$ of E-P3 75/25 PMONPs were added to $10 \mathrm{~mL}$ of distilled water, then the mixture was quickly heated to $100{ }^{\circ} \mathrm{C}$ and stirred at this temperature for $30 \mathrm{~min}$. The experiment was performed at two different pH: 7 and 1. At pH 7, we did not observe any bubbles; at pH 1 we could clearly see a lot of bubbles in the mixture (Figure 10). Then, E-P3 75/25 PMONPs were collected by centrifugation and washed with EtOH. Finally, E-P3 75/25 PMONPs were dried for FTIR analyses. At pH 7, the BOC group was still present, but at $\mathrm{pH} 1$ the absorption of $t \mathrm{Bu}\left(2987 \mathrm{~cm}^{-1}\right)$ and $\mathrm{C}=\mathrm{O}\left(1680 \mathrm{~cm}^{-1}\right)$ disappeared in the spectrum (Figure 11). These results confirmed the successful release of $\mathrm{CO}_{2}$ in $\mathrm{pH} 1$ water at $100{ }^{\circ} \mathrm{C}$.
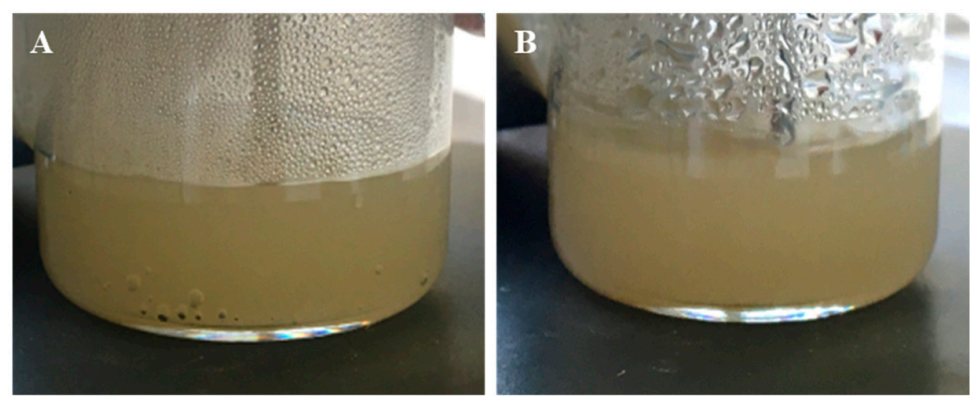

Figure 10. Images of E-P3 $75 / 25$ in water at $100^{\circ} \mathrm{C}$ and $\mathrm{pH} 1(\mathbf{A})$ at $5 \mathrm{~min}$ and (B) at $30 \mathrm{~min}$.

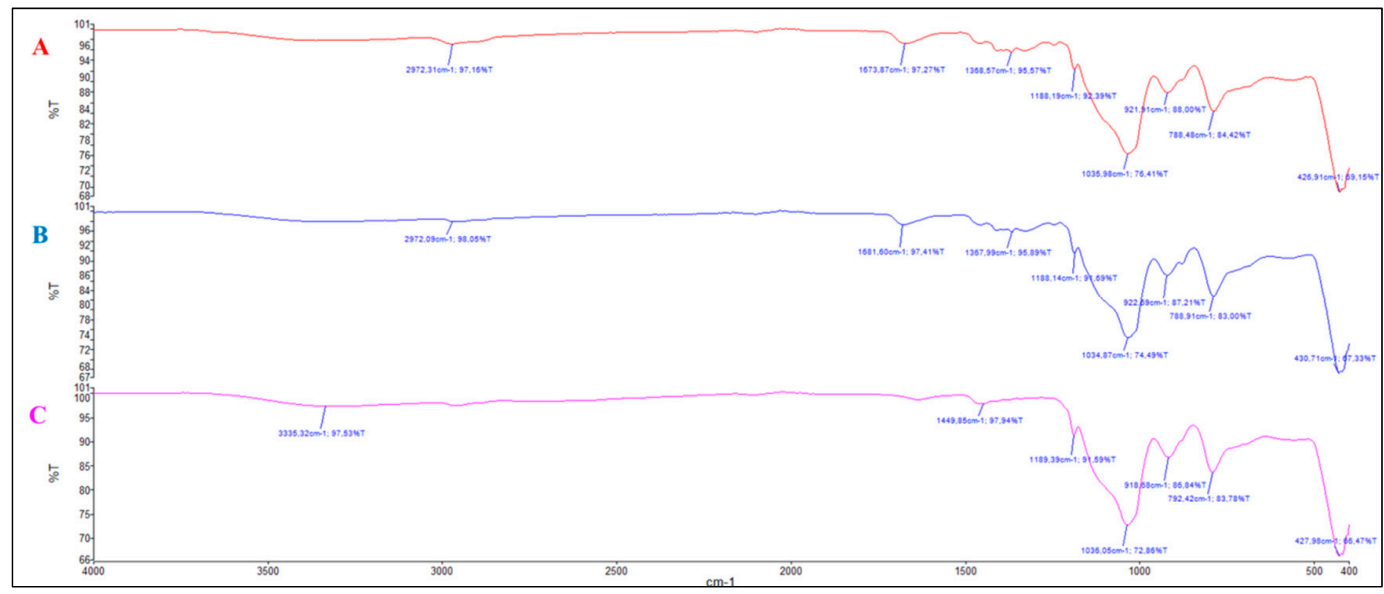

Figure 11. FTIR of E-P3 75/25 (A) before treatment, (B) after heating in distilled water, (C) after heating in water at $\mathrm{pH}=1$.

We then tried to carry out BOC removal under HIFU conditions. The different nanoparticles were suspended in water at a concentration of $10 \mathrm{mg} / \mathrm{mL}$ and submitted to HIFU, but due to the stability of BOC group in the materials, we did not observe any cleavage of the BOC group (data not shown).

\section{Materials and Methods}

\subsection{General Remarks}

The ${ }^{1} \mathrm{H}$ - and ${ }^{13} \mathrm{C}$-NMR spectra in solution were recorded on Bruker DPX-360 MHz or Avance-II $600 \mathrm{MHz}$ (Bruker Biospin, Rheinstetten, Germany) and are referenced to solvent signals $\left(\mathrm{CDCl}_{3}\right.$ : $\delta=7.26 \mathrm{ppm})$. All the spectra were calibrated using the residual solvent signal $\left(\mathrm{CHCl}_{3}, \delta_{\mathrm{H}}, 7.26\right.$ and $\delta_{\mathrm{C}}$, 77.16 ppm). Chemical shift data are expressed in ppm and coupling constant $(J)$ values in Hz. The multiplicity of peaks is abbreviated as s (singlet), $\mathrm{d}$ (doublet), $\mathrm{t}$ (triplet), q (quartet) and $\mathrm{dd}$ (doublet of doublets). These NMR instruments belong to the Servei de Ressonància Magnètica Nuclear of the Universitat Autonoma de Barcelona (UAB). The ${ }^{13} \mathrm{C}-\mathrm{CP}-\mathrm{MAS}$ solid state NMR spectra were obtained from a Varian VNMRS $300 \mathrm{MHz}$ instrument (Les Ulis, France) which belongs to the University of 
Montpellier; the repetition time was $5 \mathrm{~s}$ with contact times of five milliseconds. From the Servei d'Anàlisi Quimica of the UAB, the following experimental data were acquired: infra-red spectra (IR), mass-spectrometry (MS) and elemental analysis. IR spectroscopy was recorded with a Bruker Tensor 27 spectrometer (Bruker Biosciences Española, Madrid, Spain) using a Golden Gate ATR module with a diamond window. Low- and high-resolution mass spectra were obtained by direct injection of the sample with electrospray techniques in a Hewlett-Packard 5989A and microTOF-Q instruments (Bruker Biosciences Española, Madrid, Spain), respectively. Elemental analysis of C, N and $\mathrm{H}$ were performed using Flash 2000 Organic Elemental analyser (Barcelona, Spain) of Thermo Fisher Scientific with BBOT as an internal standard. Transmission Electron Microscopy (TEM) was performed on JEM-2011 Electron Microscope $200 \mathrm{Kv}$ (JEOL Ltd., Akishima, Tokyo, Japan), which belongs to the Servei de Microscòpia of UAB. Powder X-ray diffraction (P-XRD) was performed in the Servei de Difracció de Raigs X of UAB with X'Pert Power from PANalytical (Almelo, The Netherlands) $45 \mathrm{Kv} / 40 \mathrm{~mA}$, $\mathrm{K}_{\alpha} 1.5419 \AA$ with a cooper anode. Dynamic light scattering (DLS) and Zeta potential were obtained from University of Montpellier. DLS analyses were performed using a Cordouan Technologies DL 135 (Pessac, France) particle size analyzer instrument at University of Montpellier. Zeta potential measurements were performed on MALVERN Instruments ZETA SIZER Nano series (Orsay, France) with 1-3 mg samples dispersed in $5 \mathrm{~mL}$ of aqueous solution (distilled water or $0.01 \mathrm{M} \mathrm{NaCl}$ solution) between $\mathrm{pH} 4$ and 9. The surface areas were determined by the Brunauer-Emmet-Teller (BET) method from $\mathrm{N}_{2}$ adsorption-desorption isotherms obtained with a Micromeritics ASAP2020 analyzer (Mérignac, France) which belongs to the University of Montpellier after degassing samples for $12 \mathrm{~h}$ at $80^{\circ} \mathrm{C}$ under vacuum. The total pore volumes were evaluated by converting the volume adsorbed at $\mathrm{p} / \mathrm{p}^{\mathrm{o}} 0.98$ to the volume of liquid adsorbed (single point adsorption total pore volume of pores less than $4000 \AA$ at $\mathrm{p} / \mathrm{p}^{\circ} \approx 0.98$ ). The pore size distributions for PMONPs were determined from the desorption branch using the Barrett-Joyner-Halenda (BJH) method, which relies on the Kelvin equation to relate the width of the pores to the condensation pressure. When required, experiments were carried out with standard high vacuum and Schlenk techniques. Chromatographic purifications were performed under $\mathrm{N}_{2}$ pressure using 230-400 mesh silica gel (flash chromatography). Dry solvents and reagents were obtained following standard procedures: triethylamine was distilled over $\mathrm{CaH}_{2} ; \mathrm{DMF}, \mathrm{CH}_{3} \mathrm{CN}$ and pyridine were dried by molecular sieves, THF, $\mathrm{CH}_{2} \mathrm{Cl}_{2}$ and pentane were from solvent processing equipment (PureSolv, Innovative Technology, Newburyport, MA, USA). Cetyltrimethylammonium bromide (CTAB), sodium hydroxide, ammonium nitrate $\left(\mathrm{NH}_{4} \mathrm{NO}_{3}\right)$, and potassium bromide were purchased from Sigma-Aldrich. Absolute ethanol was purchased from Fisher Chemicals and hydrochloric acid from VWR PROLABO.

\subsection{Synthesis of $\mathbf{P} \mathbf{1}$}

To a dry $100 \mathrm{~mL}$ Schlenk flask equipped with a stir bar and under Argon atmosphere, CuI $(7.60 \mathrm{mg}$, $0.04 \mathrm{mmol})$, TBTA $(21.20 \mathrm{mg}, 0.04 \mathrm{mmol})$ and anhydrous THF $(20 \mathrm{~mL})$ were added. The resulting mixture was stirred for $30 \mathrm{~min}$, then (3-azidopropyl)triethoxysilane (988.5 mg, $4.0 \mathrm{mmol})$, tert-butyl di(prop-2-yn-1-yl)carbamate $\left(463.46 \mathrm{mg}, 2.4 \mathrm{mmol}\right.$ ) and anhydrous $\mathrm{Et}_{3} \mathrm{~N}(1.0 \mathrm{~mL}, 0.73 \mathrm{~g} / \mathrm{mL} 7.2 \mathrm{mmol})$ were added by using a syringe. The resulting mixture was stirred at $50{ }^{\circ} \mathrm{C}$ (Argon atmosphere) until tert-butyl di(prop-2-yn-1-yl)carbamate was fully consumed (16 h, reaction monitored by TLC). Then, the solvent was evaporated under reduced pressure and the residue was washed with cold anhydrous pentane to remove some remaining azide. Hot anhydrous pentane was added to the insoluble fraction to extract the disilylated product; this digestion with hot pentane was repeated several times and the pentane extracts were concentrated under reduced pressure to provide the pure product as a colorless oil $(999 \mathrm{mg}$, $73 \%$ yield). ${ }^{1} \mathrm{H}-\mathrm{NMR}\left(360 \mathrm{MHz}, \mathrm{CDCl}_{3}\right) \delta 7.53(\mathrm{~s}, 1 \mathrm{H}), 7.42(\mathrm{~s}, 1 \mathrm{H}), 4.51(\mathrm{~s}, 4 \mathrm{H}), 4.29(\mathrm{t}, J=7.2 \mathrm{~Hz}, 4 \mathrm{H})$, $3.78(\mathrm{q}, J=7.2 \mathrm{~Hz}, 12 \mathrm{H}), 2.00-1.96(\mathrm{~m}, 4 \mathrm{H}), 1.42(\mathrm{~s}, 9 \mathrm{H}), 1.17(\mathrm{t}, J=7.2 \mathrm{~Hz}, 18 \mathrm{H}), 0.56(\mathrm{t}, J=7.2 \mathrm{~Hz}, 4 \mathrm{H})$; ${ }^{13} \mathrm{C}-\mathrm{NMR}\left(91 \mathrm{MHz}, \mathrm{CDCl}_{3}\right) \delta 155.2,122.7,121.9,80.3,58.5,58.4,52.4,28.4,24.2,18.2,7.4$. IR (film) 3132.4, 2973.6, 2927.2, 1692.6, 1390.2, 1163.5, 1073.1, 954.5, $783.2 \mathrm{~cm}^{-1}$. MS (ESI) $\mathrm{m} / \mathrm{z}: 688.4,632.3,588.3,558.3$; HRMS (ESI) $m / z$ [M + Na] calcd. for $\mathrm{C}_{29} \mathrm{H}_{57} \mathrm{~N}_{7} \mathrm{O}_{8} \mathrm{Si}_{2} \mathrm{Na}$ : 688.3880, found: 688.3877 . 


\subsection{Synthesis of $\boldsymbol{P} \mathbf{2}$}

To a dry, $100 \mathrm{~mL}$ Schlenk flask equipped with a stir bar and under Argon atmosphere, CuI $(7.60 \mathrm{mg}, 0.04 \mathrm{mmol})$, TBTA $(21.20 \mathrm{mg}, 0.04 \mathrm{mmol})$ and anhydrous THF $(20 \mathrm{~mL})$ were added. The resulting mixture was stirred for $30 \mathrm{~min}$, and then $\mathrm{N}$-(2-azidoethyl)-3-(triethoxysilyl) - $N$-(3-(triethoxysilyl)propyl)propan-1-amine (1.98 g, $4.0 \mathrm{mmol}$ ), tert-butyl di(prop-2-yn-1-yl)carbamate $(463.46 \mathrm{mg}, 2.4 \mathrm{mmol})$ and anhydrous $\mathrm{Et}_{3} \mathrm{~N}(1.0 \mathrm{~mL}, 0.73 \mathrm{~g} / \mathrm{mL}, 7.2 \mathrm{mmol})$ were added by using a syringe. The resulting mixture was stirred at $50{ }^{\circ} \mathrm{C}$ (Argon atmosphere) until tert-butyl di(prop-2-yn-1-yl)carbamate was fully consumed ( $20 \mathrm{~h}$, reaction monitored by TLC). Then, the solvent was partially evaporated under reduced pressure, the remaining solution was filtered through Whatman ${ }^{\circledR}$ membrane filters PTFE (pore size $0.2 \mu \mathrm{m}$, diam. $47 \mathrm{~mm}$ ) and the filtrate evaporated at reduced pressure to afford the final product as colorless oil $\left(2.27 \mathrm{~g}, 96 \%\right.$ yield). ${ }^{1} \mathrm{H}-\mathrm{NMR}(360 \mathrm{MHz}$, $\left.\mathrm{CDCl}_{3}\right) \delta 7.61(\mathrm{~s}, 1 \mathrm{H}), 7.57(\mathrm{~s}, 1 \mathrm{H}), 4.51(\mathrm{~s}, 4 \mathrm{H}), 4.36(\mathrm{t}, J=7.2 \mathrm{~Hz}, 4 \mathrm{H}), 3.80(\mathrm{q}, J=7.2 \mathrm{~Hz}, 24 \mathrm{H}), 2.88$ $(\mathrm{t}, J=7.2 \mathrm{~Hz}, 4 \mathrm{H}), 2.47(\mathrm{t}, J=7.2 \mathrm{~Hz}, 8 \mathrm{H}), 1.53-1.45(\mathrm{~m}, 17 \mathrm{H}), 1.20(\mathrm{t}, J=7.2 \mathrm{~Hz}, 36 \mathrm{H}), 0.54(\mathrm{t}, J=7.2 \mathrm{~Hz}$, 8H); ${ }^{13} \mathrm{C}-\mathrm{NMR}\left(91 \mathrm{MHz}, \mathrm{CDCl}_{3}\right) \delta 155.1,128.9,127.9,80.1,58.2,57.0,54.1,48.8,28.3,28.1,20.2,18.1,7.7$. IR (film): 2972.4, 2927.2, 2882.9, 1695.7, 1457.0, 1389.6, 1164.1, 1073.0, 952.5, $770.1 \mathrm{~cm}^{-1}$. MS (ESI) $\mathrm{m} / z$ : 1204.7, 1182.7, 688.4, 591.9, 413.3; HRMS (ESI) $m / z$ [M + Na] $]^{+}$calcd. for $\mathrm{C}_{51} \mathrm{H}_{107} \mathrm{~N}_{9} \mathrm{O}_{14} \mathrm{Si}_{4} \mathrm{Na}$ : 1204.6906 , found: 1204.6894 .

\subsection{Synthesis of $\boldsymbol{P} 3$}

To a dry, $100 \mathrm{~mL}$ Schlenk flask equipped with a stir bar and under Argon atmosphere, CuI $(7.60 \mathrm{mg}$, $0.04 \mathrm{mmol})$, TBTA $(21.20 \mathrm{mg}, 0.04 \mathrm{mmol})$ and anhydrous THF $(20 \mathrm{~mL})$ were added. The resulting mixture was stirred for $30 \mathrm{~min}$, then 3-azido- $N, N$-bis(3-(triethoxysilyl)propyl)propan-1-amine (2.03 g, $4.0 \mathrm{mmol})$, tert-butyl di(prop-2-yn-1-yl)carbamate $(463.46 \mathrm{mg}, 2.4 \mathrm{mmol})$ and anhydrous $\mathrm{Et}_{3} \mathrm{~N}(1.0 \mathrm{~mL}$, $0.73 \mathrm{~g} / \mathrm{mL}, 7.2 \mathrm{mmol}$ ) were added by using a syringe. The resulting mixture was stirred at $50{ }^{\circ} \mathrm{C}$ (Argon atmosphere) until tert-butyl di(prop-2-yn-1-yl)carbamate was fully consumed ( $20 \mathrm{~h}$, reaction monitored by TLC). Then, the solvent was partially evaporated under reduced pressure, the remaining solution was filtered through Whatman ${ }^{\circledR}$ membrane filters PTFE (pore size $0.2 \mu \mathrm{m}$, diam. $47 \mathrm{~mm}$ ) and the filtrate was evaporated at reduced pressure to afford the final product as colorless oil (2.33 g, 96\% yield). ${ }^{1} \mathrm{H}-\mathrm{NMR}\left(360 \mathrm{MHz}, \mathrm{CDCl}_{3}\right) \delta 7.55(\mathrm{~s}, 1 \mathrm{H}), 7.47(\mathrm{~s}, 1 \mathrm{H}), 4.53(\mathrm{~s}, 4 \mathrm{H}), 4.36(\mathrm{t}, J=7.2 \mathrm{~Hz}$, $4 \mathrm{H}), 3.81(\mathrm{q}, J=7.2 \mathrm{~Hz}, 24 \mathrm{H}), 2.48-2.36(\mathrm{~m}, 12 \mathrm{H}), 2.01(\mathrm{t}, J=7.2 \mathrm{~Hz}, 4 \mathrm{H}), 1.52-1.46(\mathrm{~m}, 17 \mathrm{H}), 1.21$ $(\mathrm{t}, J=7.2 \mathrm{~Hz}, 36 \mathrm{H}), 0.57(\mathrm{t}, J=7.2 \mathrm{~Hz}, 8 \mathrm{H}) ;{ }^{13} \mathrm{C}-\mathrm{NMR}\left(91 \mathrm{MHz}, \mathrm{CDCl}_{3}\right) \delta 155.2,129.1,128.0,80.3,58.3$, 57.1, 56.8, 50.9, 48.5, 28.4, 26.8, 20.1, 18.3, 7.9. IR (film) 2972.7, 2926.8, 2883.2, 1695.4, 1455.6, 1389.7, 1164.0, 1072.8, 952.5, 770.3 $\mathrm{cm}^{-1}$. MS (ESI) $\mathrm{m} / z: 1232.7,1210.7,816.5,702.4,605.9,509.3,438.3$; HRMS (ESI) $m / z[\mathrm{M}+\mathrm{Na}]^{+}$calcd. for $\mathrm{C}_{53} \mathrm{H}_{111} \mathrm{~N}_{9} \mathrm{O}_{14} \mathrm{Si}_{4} \mathrm{Na}$ : 1232.7220 , found: 1232.7195 .

\subsection{Synthesis of $\boldsymbol{E}-\boldsymbol{B} T S E$}

Grubbs Catalyst ${ }^{\mathrm{TM}}$ 1st Generation $\mathrm{C} 823 \quad\left(\mathrm{PCy}_{3}\right)_{2} \mathrm{Cl}_{2} \mathrm{Ru}=\mathrm{CHPh} \quad(82.30 \mathrm{mg}, 0.1 \mathrm{mmol})$ and vinyltriethoxysilane (VTES) $(19.02 \mathrm{~g}, 100 \mathrm{mmol})$ were added to a Schlenk flask under argon. After the solution was stirred for one hour and the mixture was refluxed for $24 \mathrm{~h}$, unreacted VTES was distilled off. Subsequently, BTSE was vacuum distilled to give a clear colorless liquid (12.53 g, 71\% yield, 4 mbar, $124^{\circ} \mathrm{C}$ ). E-BTSE was identified by ${ }^{1} \mathrm{H}$-NMR as a diastereoisomerically pure product $(100 \% E) .{ }^{1} \mathrm{H}-\mathrm{NMR}\left(360 \mathrm{MHz}, \mathrm{CDCl}_{3}\right) \delta 6.66(\mathrm{~s}, 2 \mathrm{H}$; E-isomer), 3.83 (q, J = 7.2 Hz, $12 \mathrm{H}), 1.23$ $(\mathrm{t}, J=7.2 \mathrm{~Hz}, 18 \mathrm{H})$.

\subsection{Preparation of E-BTSE PMONPs}

In an open $250 \mathrm{~mL}$ round-bottom flask without reflux condenser, a solution of cetyltrimethylammonium bromide (CTAB, $250 \mathrm{mg}, 0.686 \mathrm{mmol})$ was placed in Mili-Q water $(120 \mathrm{~mL})$ and then $875 \mu \mathrm{L}$ of $2 \mathrm{M} \mathrm{NaOH}$ was added $(1.75 \mathrm{mmol}$ of $\mathrm{NaOH})$. The mixture was stirred at $1000 \mathrm{rpm}$ at $80^{\circ} \mathrm{C}$ for $50 \mathrm{~min}$. Then, the stirring speed was enhanced to $1400 \mathrm{rpm}$ and 1,2-bis(triethoxysilyl)ethene 
(BTSE, $800 \mu \mathrm{L}, 2.29 \mathrm{mmol}$ ) was added rapidly under stirring. The condensation process was conducted for two hours at $80^{\circ} \mathrm{C}$. The suspension was cooled to room temperature while stirring and the NPs were collected by centrifugation (13,500 rpm in $6 \times 25 \mathrm{~mL}$ flasks tubes for $45 \mathrm{~min})$. The supernatant was removed and an aliquot of the solid was taken and dried for FTIR. In order to remove the surfactant, $10 \mathrm{~mL}$ of an alcoholic solution of ammonium nitrate $\left[\mathrm{NH}_{4} \mathrm{NO}_{3}, 6 \mathrm{~g} / \mathrm{L}\right.$ in $\left.96 \% \mathrm{EtOH}\right]$ was added to each tube. The six tubes were sonicated for $30 \mathrm{~min}$ at $50{ }^{\circ} \mathrm{C}$, then cooled and centrifuged ( $30 \mathrm{~min}$ at $13,500 \mathrm{rpm}$ at $25^{\circ} \mathrm{C}$ ), the supernatant was discarded. This $\mathrm{NH}_{4} \mathrm{NO}_{3}$ washing was performed three times. Each solid in the tubes was washed successively with $96 \%$ ethanol, Mili-Q water, $96 \%$ ethanol using the same protocol ( $30 \mathrm{~min}$ at $50{ }^{\circ} \mathrm{C}$ sonication, centrifugation). The final product was dried for few hours under vacuum at room temperature. The E PMONPs were obtained as a white solid. At the same time, another aliquot of the solid was taken and dried for FTIR. It was compared to the IR of the sample before removal of the surfactant and after removal to check whether the $\mathrm{CH}_{2}$ bands of CTAB had completely disappeared.

\subsection{Preparation of E-Pn 90/10 PMONPs}

In an open $250 \mathrm{~mL}$ round-bottom flask without reflux condenser, a solution of CTAB $(250 \mathrm{mg}$, $0.686 \mathrm{mmol})$ was placed in Mili-Q water $(120 \mathrm{~mL})$ and then $875 \mu \mathrm{L}$ of $2 \mathrm{M} \mathrm{NaOH}$ was added $(1.75 \mathrm{mmol}$ of $\mathrm{NaOH}$ ). The mixture was stirred at $1000 \mathrm{rpm}$ at $80^{\circ} \mathrm{C}$ for $50 \mathrm{~min}$. Then, the stirring speed was enhanced to $1400 \mathrm{rpm}$ and a mixture of 100\% E-BTSE (704.34 mg, $2.00 \mathrm{mmol})$ with Pn $(0.2 \mathrm{mmol})$ were added rapidly under stirring. The condensation process was conducted for two hours at $80{ }^{\circ} \mathrm{C}$. Afterwards, the suspension was cooled to room temperature while stirring and the NPs were collected by centrifugation during $45 \mathrm{~min}$ at 13,500 rpm. The samples were then extracted three times with a solution of $\mathrm{NH}_{4} \mathrm{NO}_{3}(6 \mathrm{~g} / \mathrm{L}$ in $96 \% \mathrm{EtOH})$, and washed three times with $96 \%$ ethanol, Mili-Q water, $96 \%$ ethanol, respectively. Extraction and the following steps were identical to those described for E PMONPs. The E-Pn 90/10 PMONPs were obtained as a white solid. E-P1 90/10 PMONPs: ${ }^{13}$ C-CP-MAS NMR $(75 \mathrm{MHz}) \delta$ : 155.6, 146.1, 123.8, 81.1, 57.9, 52.5, 28.2, 24.9, 17.4, 10.4. IR $v$ (ATR) $\left(\mathrm{cm}^{-1}\right): 3337.7,1671.3,1416.6,1187.7,1036.9,927.3$. BET: $\mathrm{S}_{\mathrm{BET}}=683 \mathrm{~m}^{2} \cdot \mathrm{g}^{-1}, \mathrm{~V}_{\text {pore }}=0.48 \mathrm{~cm}^{3} \cdot \mathrm{g}^{-1}$, $\emptyset_{\text {pore }}=2.8 \mathrm{~nm}$. TGA (air, $5{ }^{\circ} \mathrm{C} / \mathrm{min}, 20-1000{ }^{\circ} \mathrm{C}$ ) residual mass $78 \%$. Zeta Potential: $\zeta=-28.7 \mathrm{mV}$,

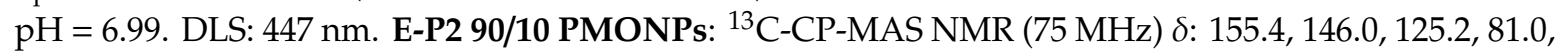
58.1, 52.8, 48.2, 28.5, 20.6, 10.8. IR $v$ (ATR) $\left(\mathrm{cm}^{-1}\right): 3322.9,1673.0,1412.0,1187.7,1036.2,923.7,187.9$. BET: $\mathrm{S}_{\mathrm{BET}}=509 \mathrm{~m}^{2} \cdot \mathrm{g}^{-1}, \mathrm{~V}_{\text {pore }}=0.34 \mathrm{~cm}^{3} \cdot \mathrm{g}^{-1}, \emptyset_{\text {pore }}=2.7 \mathrm{~nm}$. TGA (air, $5^{\circ} \mathrm{C} / \mathrm{min}, 20-1000^{\circ} \mathrm{C}$ ) residual mass 75\%. Zeta Potential: $\zeta=32.6 \mathrm{mV}, \mathrm{pH}=5.92$. DLS: $800 \mathrm{~nm}$. E-P3 90/10 PMONPs: ${ }^{13} \mathrm{C}-\mathrm{CP}-\mathrm{MAS}$ NMR (75 MHz) $\delta: ~ 156.1,146.1,124.7,81.0,58.0,48.0,28.4,18.5,10.6$. IR $v$ (ATR) $\left(\mathrm{cm}^{-1}\right): 3361.9,1655.6$, $1370.1,1188.0,1033.4,924.1,788.8$. BET: $S_{\text {BET }}=505 \mathrm{~m}^{2} \cdot \mathrm{g}^{-1}, \mathrm{~V}_{\text {pore }}=0.66 \mathrm{~cm}^{3} \cdot \mathrm{g}^{-1}, \emptyset_{\text {pore }}=2.8 \mathrm{~nm}$. TGA (air, $5{ }^{\circ} \mathrm{C} / \mathrm{min}, 20-1000{ }^{\circ} \mathrm{C}$ ) residual mass $72 \%$. Zeta Potential: $\zeta=36.0 \mathrm{mV}, \mathrm{pH}=5.44$. DLS: $479 \mathrm{~nm}$.

\subsection{Preparation of $\mathbf{E}-\mathrm{Pn} 75 / 25$ PMONPs}

In an open $250 \mathrm{~mL}$ round-bottom flask without reflux condenser a solution of CTAB (250 mg, $0.686 \mathrm{mmol})$ was placed in Mili-Q water $(120 \mathrm{~mL})$ and then $875 \mu \mathrm{L}$ of $2 \mathrm{M} \mathrm{NaOH}$ was added $(1.75 \mathrm{mmol}$ of $\mathrm{NaOH}$ ). The mixture was stirred at $1000 \mathrm{rpm}$ at $80^{\circ} \mathrm{C}$ for $50 \mathrm{~min}$. Then, the stirring speed was enhanced to $1400 \mathrm{rpm}$ and a mixture of $100 \%$ E-BTSE (581.09 $\mathrm{mg}, 1.65 \mathrm{mmol})$ with Pn $(0.55 \mathrm{mmol})$ were added rapidly under stirring. The condensation process was conducted for two hours at $80{ }^{\circ} \mathrm{C}$. Afterwards, the suspension was cooled to room temperature while stirring and the NPs were collected by centrifugation during $45 \mathrm{~min}$ at 13,500 rpm. The samples were then extracted three times with a solution of $\mathrm{NH}_{4} \mathrm{NO}_{3}(6 \mathrm{~g} / \mathrm{L}$ in $96 \% \mathrm{EtOH})$, and washed three times with $96 \%$ ethanol, Mili-Q water, $96 \%$ ethanol, respectively. Extraction and the following steps were identical to those described for E PMONPs. The E-Pn 75/25 PMONPs were obtained as a white solid. E-P1 75/25 PMONPs: ${ }^{13}$ C-CP-MAS NMR (75 MHz) $\delta:$ 156.1, 145.5, 123.6, 81.9, 57.7, 52.8, 28.3, 24.8, 17.9, 10.4. IR $v$ (ATR) $\left(\mathrm{cm}^{-1}\right): 3302.3,1670.8,1414.8,1186.9,1012.0,926.6,784.0$. TGA (air, $5{ }^{\circ} \mathrm{C} / \mathrm{min}, 20-1000{ }^{\circ} \mathrm{C}$ ) residual mass 67\%. Zeta Potential: $\zeta=-22.9 \mathrm{mV}, \mathrm{pH}=7.34$. DLS: 507 nm. E-P2 75/25 PMONPs: ${ }^{13} \mathrm{C}-\mathrm{CP}-\mathrm{MAS}$ 
NMR (75 MHz) $\delta: 155.7,145.5,125.3,80.2,57.8,28.4,21.7,11.1$. IR $v$ (ATR) $\left(\mathrm{cm}^{-1}\right): 3331.9,1672.4$, 1412.3, 1186.7, 1011.4, 923.1, 785.6. TGA (air, $5^{\circ} \mathrm{C} / \mathrm{min}, 20-1000^{\circ} \mathrm{C}$ ) residual mass $58 \%$. Zeta Potential: $\zeta=19.9 \mathrm{mV}, \mathrm{pH}=6.25$. DLS: 513 nm. E-P3 75/25 PMONPs: ${ }^{13} \mathrm{C}-\mathrm{CP}-M A S$ NMR $(75 \mathrm{MHz}) \delta: 1561.2$, 146.1, 124.8, 81.7, 58.2, 48.8, 28.6, 19.8, 10.3. IR $v$ (ATR) $\left(\mathrm{cm}^{-1}\right): 3294.2,1676.8,1388.2,1012.7,923.4$, 786.5. TGA (air, $5{ }^{\circ} \mathrm{C} / \mathrm{min}, 20-1000{ }^{\circ} \mathrm{C}$ ) residual mass $57 \%$. Zeta Potential: $\zeta=24.2 \mathrm{mV}, \mathrm{pH}=4.85$. DLS: $321 \mathrm{~nm}$.

\subsection{Synthesis of P3 PMONPs}

In an open $100 \mathrm{~mL}$ round-bottom flask without reflux condenser a solution of CTAB (125 mg, $0.34 \mathrm{mmol})$ was placed in Mili-Q water $(60 \mathrm{~mL})$ and then $437 \mu \mathrm{L}$ of $2 \mathrm{M} \mathrm{NaOH}$ was added. The mixture was stirred at $1000 \mathrm{rpm}$ at $80^{\circ} \mathrm{C}$ for $50 \mathrm{~min}$. Then, the stirring speed was enhanced to $1400 \mathrm{rpm}$ and P3 $(0.1 \mathrm{mmol})$ in absolute ethanol $(1.0 \mathrm{~mL})$ was added rapidly under stirring. The condensation process was conducted for $24 \mathrm{~h}$ at $80^{\circ} \mathrm{C}$. Afterwards, the suspension was cooled to room temperature while stirring and the NPs were collected by centrifugation during $15 \mathrm{~min}$ at 20,000 rpm. The samples were then extracted twice with a solution of $\mathrm{NH}_{4} \mathrm{NO}_{3}(6 \mathrm{~g} / \mathrm{L}$ in $\mathrm{EtOH})$, and washed three times with ethanol, Mili-Q water, ethanol, respectively. Extraction and the following steps were identical to those described for E PMONPs. P3 PMONPs were obtained as a white solid. IR $v$ (ATR) (cm $\left.{ }^{-1}\right)$ : 3395.7, 2936.4, 1682.3, 1367.4, 1103.1, 1023.6, 783.8, 688.4. BET: $\mathrm{S}_{\mathrm{BET}}=186 \mathrm{~m}^{2} \cdot \mathrm{g}^{-1}, \mathrm{~V}_{\text {pore }}=0.26 \mathrm{~cm}^{3} \cdot \mathrm{g}^{-1}, \emptyset_{\text {pore }}=5.64 \mathrm{~nm}$. Zeta Potential: $\zeta=10.9 \mathrm{mV}, \mathrm{pH}=8.94$. DLS: $269 \mathrm{~nm}$.

\subsection{HIFU Stimulation}

Nanoparticles were resuspended in PBS at a concentration of $10 \mathrm{mg} / \mathrm{mL}$ in an eppendorf tube. The tube was submitted to an ultrasound field from a focused $1 \mathrm{MHz}$ probe (Precision Acoustics, UK) driven by a signal generator (Agilent 33220a, Les Ulis, France) and RF power amplifier (ADECE, Artannes sur Indre, France). The transducer was placed in a custom-made three-axis motorized positioning system to send ultrasound accurately on the eppendorf tube at the focus of the probe. Degased water was applied between the transducer and the eppendorf tube. Peak negative pressures of 1.0, 1.4 and 1.6 MPa in continuous mode were used in this study. Ultrasound stimulation time was set to $15 \mathrm{~s}$. The transducer was calibrated using an HGL-200 PVDF bullet type hydrophone (Onda, Sunnyvale, CA, USA), at the focus distance of the transducer.

\section{Conclusions}

In conclusion, we studied the preparation of nanomaterials possessing a BOC group. Molecules with BOC and two to four triethoxysilyl groups were successfully synthesized through click chemistry. Then, the molecules were reacted through the sol gel procedure with bis(triethoxysilyl)ethylene, at a proportion of $10 / 90$ to $25 / 75$, and the materials were analyzed with different techniques. The nanorods E-P1, E-P2, E-P3, at a proportion of 90/10, possessed small wormlike mesopores, while, at a proportion of $75 / 25$, the nanomaterials were non-porous at $78 \mathrm{~K}$. The BOC group was not damaged during the sol gel-procedure, as shown by FTIR and ${ }^{13} \mathrm{C}$ CPMAS solid-state NMR. TGA showed the stability of BOC group inside the materials, as no decomposition occurred before $120^{\circ} \mathrm{C}$. Alternatively, P3 PMONPs were synthesized from molecule $\mathbf{P} 3$ without any other source of silicate. The obtained nanoparticles were of $100 \mathrm{~nm}$ diameter, and were mesoporous with a porosity of $5.6 \mathrm{~nm}$. The BOC was very stable as we needed to adjust the $\mathrm{pH}$ to 1 to cleave the $\mathrm{BOC}$ at $100{ }^{\circ} \mathrm{C}$. We were not able to observe bubbles at $\mathrm{pH} 5.5$ under our conditions of HIFU, but the concept is nevertheless promising for future contrast agents for HIFU. Indeed, the electrophilicity of BOC has been shown to strongly influence the reaction rate and reactivity of the cleavage. [37] Therefore, the synthesis of precursor molecules possessing more electrophilic BOC groups can be considered. Another possibility is to introduce carboxylic acid functions in the PMONPs using triethoxysilanes possessing this function [38] during the sol-gel procedure, in order to facilitate BOC cleavage in the materials. 
Author Contributions: Conceptualization, R.P., P.M., C.P. and J.-O.D.; methodology, H.L., C.G. and A.D.; formal analysis, C.C., R.P. and J.-O.D.; writing — original draft preparation, H.L., J.-O.D. and R.P., writing-review and editing, L.R.; supervision, R.P., J.-O.D. and C.P. All authors have read and agreed to the published version of the manuscript.

Funding: This research was funded by CNRS (France), Ministerio de Economía, Industria y Competitividad (MINECO) of Spain (Projects CTQ2014-53662-P and CTQ2016-81797-REDC), Ministerio de Ciencia, Innovación y Universidades (MCIU) of Spain (Project RTI2018-097853-B-I00 and RED2018-102387-T), DURSI-Generalitat de Catalunya (Project SGR2017-0465) and China Scholarship Council (CSC) (predoctoral scholarship to Hao Li, CSC No. 201606890025).

Acknowledgments: The authors are grateful to China Scholarship Council (CSC) for predoctoral scholarships to H.L.

Conflicts of Interest: The authors declare no conflict of interest.

\section{References}

1. Du, X.; Li, X.; Xiong, L.; Zhang, X.; Kleitz, F.; Qiao, S.Z. Mesoporous silica nanoparticles with organo-bridged silsesquioxane framework as innovative platforms for bioimaging and therapeutic agent delivery. Biomaterials 2016, 91, 90-127. [CrossRef] [PubMed]

2. Chen, Y.; Shi, J. Chemistry of Mesoporous Organosilica in Nanotechnology: Molecularly Organic-Inorganic Hybridization into Frameworks. Adv. Mater. 2016, 28, 3235-3272. [CrossRef]

3. Croissant, J.G.; Cattoen, X.; Wong Chi Man, M.; Durand, J.-O.; Khashab, N.M. Syntheses and applications of periodic mesoporous organosilica nanoparticles. Nanoscale 2015, 7, 20318-20334. [CrossRef] [PubMed]

4. Teng, Z.; Li, W.; Tang, Y.; Elzatahry, A.; Lu, G.; Zhao, D. Mesoporous Organosilica Hollow Nanoparticles: Synthesis and Applications. Adv. Mater. 2018, 1707612. [CrossRef] [PubMed]

5. Manzano, M.; Vallet-Regi, M. Mesoporous silica nanoparticles for drug delivery. Adv. Funct. Mater. 2019. [CrossRef]

6. Li, Z.; Zhang, Y.; Feng, N. Mesoporous silica nanoparticles: Synthesis, classification, drug loading, pharmacokinetics, biocompatibility, and application in drug delivery. Expert Opin. Drug Delivery 2019, 16, 219-237. [CrossRef]

7. $\quad$ Li, T.; Shi, S.; Goel, S.; Shen, X.; Xie, X.; Chen, Z.; Zhang, H.; Li, S.; Qin, X.; Yang, H.; et al. Recent advancements in mesoporous silica nanoparticles towards therapeutic applications for cancer. Acta Biomater. 2019, 89, 1-13. [CrossRef]

8. Chen, W.; Glackin, C.A.; Horwitz, M.A.; Zink, J.I. Nanomachines and Other Caps on Mesoporous Silica Nanoparticles for Drug Delivery. Acc. Chem. Res. 2019, 52, 1531-1542. [CrossRef]

9. Zhu, J.; Niu, Y.; Li, Y.; Gong, Y.; Shi, H.; Huo, Q.; Liu, Y.; Xu, Q. Stimuli-responsive delivery vehicles based on mesoporous silica nanoparticles: Recent advances and challenges. J. Mater. Chem. B 2017, 5, 1339-1352. [CrossRef]

10. Castillo, R.R.; Colilla, M.; Vallet-Regi, M. Advances in mesoporous silica-based nanocarriers for co-delivery and combination therapy against cancer. Expert Opin. Drug Delivery 2017, 14, 229-243. [CrossRef]

11. Pasqua, L.; Leggio, A.; Sisci, D.; Ando, S.; Morelli, C. Mesoporous Silica Nanoparticles in Cancer Therapy: Relevance of the Targeting Function. Mini-Rev. Med. Chem. 2016, 16, 743-753. [CrossRef] [PubMed]

12. Moreira, A.F.; Dias, D.R.; Correia, I.J. Stimuli-responsive mesoporous silica nanoparticles for cancer therapy: A review. Microporous Mesoporous Mater. 2016, 236, 141-157. [CrossRef]

13. Croissant, J.G.; Fatieiev, Y.; Almalik, A.; Khashab, N.M. Mesoporous Silica and Organosilica Nanoparticles: Physical Chemistry, Biosafety, Delivery Strategies, and Biomedical Applications. Adv. Healthc. Mater. 2018, 7, 1700831. [CrossRef] [PubMed]

14. Croissant, J.G.; Fatieiev, Y.; Khashab, N.M. Degradability and Clearance of Silicon, Organosilica, Silsesquioxane, Silica Mixed Oxide, and Mesoporous Silica Nanoparticles. Adv. Mater. 2017, 29, 1604634. [CrossRef] [PubMed]

15. Moeller, K.; Bein, T. Degradable Drug Carriers: Vanishing Mesoporous Silica Nanoparticles. Chem. Mater. 2019, 31, 4364-4378. [CrossRef]

16. Du, X.; Kleitz, F.; Li, X.; Huang, H.; Zhang, X.; Qiao, S.Z. Disulfide-Bridged Organosilica Frameworks: Designed, Synthesis, Redox-Triggered Biodegradation, and Nanobiomedical Applications. Adv. Funct. Mater. 2018, 1707325. [CrossRef] 
17. Manzano, M.; Vallet-Regi, M. Ultrasound responsive mesoporous silica nanoparticles for biomedical applications. Chem. Commun. 2019, 55, 2731-2740. [CrossRef]

18. Cheng, C.-A.; Chen, W.; Zhang, L.; Wu, H.H.; Zink, J.I. A Responsive Mesoporous Silica Nanoparticle Platform for Magnetic Resonance Imaging-Guided High-Intensity Focused Ultrasound-Stimulated Cargo Delivery with Controllable Location, Time, and Dose. J. Am. Chem. Soc. 2019, 141, 17670-17684. [CrossRef]

19. Chen, Y.; Ma, M.; Chen, H.; Shi, J. Multifunctional hollow mesoporous silica nanoparticles for MR/US imaging-guided tumor therapy. Springer Ser. Biomater. Sci. Eng. 2016, 7, 189-222. [CrossRef]

20. Liu, T.; Zhang, N.; Wang, Z.; Wu, M.; Chen, Y.; Ma, M.; Chen, H.; Shi, J. Endogenous Catalytic Generation of O2 Bubbles for In Situ Ultrasound-Guided High Intensity Focused Ultrasound Ablation. ACS Nano 2017, 11, 9093-9102. [CrossRef]

21. Chen, Y.; Meng, Q.; Wu, M.; Wang, S.; Xu, P.; Chen, H.; Li, Y.; Zhang, L.; Wang, L.; Shi, J. Hollow Mesoporous Organosilica Nanoparticles: A Generic Intelligent Framework-Hybridization Approach for Biomedicine. J. Am. Chem. Soc. 2014, 136, 16326-16334. [CrossRef] [PubMed]

22. Qian, X.; Wang, W.; Kong, W.; Chen, Y. Hollow periodic mesoporous organosilicas for highly efficient HIFU-based synergistic therapy. RSC Adv. 2014, 4, 17950-17958. [CrossRef]

23. Phenix, C.P.; Togtema, M.; Pichardo, S.; Zehbe, I.; Curiel, L. High intensity focused ultrasound technology, its scope and applications in therapy and drug delivery. J. Pharm. Pharm. Sci. 2014, 17, 136-153. [CrossRef] [PubMed]

24. Mason, T.J. Therapeutic ultrasound an overview. Ultrason. Sonochem. 2011, 18, 847-852. [CrossRef] [PubMed]

25. Izadifar, Z.; Babyn, P.; Chapman, D. Ultrasound Cavitation/Microbubble Detection and Medical Applications. J. Med. Biol. Eng. 2019, 39, 259-276. [CrossRef]

26. Yoon, Y.I.; Tang, W.; Chen, X. Ultrasound-Mediated Diagnosis and Therapy based on Ultrasound Contrast Agents. Small Methods 2017, 1, 1700173. [CrossRef]

27. Wen, Q.; Wan, S.; Liu, Z.; Xu, S.; Wang, H.; Yang, B. Ultrasound contrast agents and ultrasound molecular imaging. J. Nanosci. Nanotechnol. 2014, 14, 190-209. [CrossRef]

28. Lin, Y.-J.; Huang, C.-C.; Wan, W.-L.; Chiang, C.-H.; Chang, Y.; Sung, H.-W. Recent advances in CO2 bubble-generating carrier systems for localized controlled release. Biomaterials 2017, 133, 154-164. [CrossRef]

29. Zinelaabidine, C.; Souad, O.; Zoubir, J.; Malika, B.; Nour-Eddine, A. A simple and efficient green method for the deprotection of N-Boc in various structurally diverse amines under water-mediated catalyst-free conditions. Int. J. Chem. 2012, 4, 73-79. [CrossRef]

30. Wang, J.; Liang, Y.-L.; Qu, J. Boiling water-catalyzed neutral and selective N-Boc deprotection. Chem. Commun. 2009, 5144-5146. [CrossRef]

31. Qian, X.; Han, X.; Chen, Y. Insights into the unique functionality of inorganic micro/nanoparticles for versatile ultrasound theranostics. Biomaterials 2017, 142, 13-30. [CrossRef] [PubMed]

32. Gruell, H.; Langereis, S. Hyperthermia-triggered drug delivery from temperature-sensitive liposomes using MRI-guided high intensity focused ultrasound. J. Control. Release 2012, 161, 317-327. [CrossRef] [PubMed]

33. Bürglová, K.; Moitra, N.; Hodacová, J.; Cattoën, X.; Wong Chi Man, M. Click Approaches to Functional Water-Sensitive Organotriethoxysilanes. J. Org. Chem. 2011, 76, 7326-7333. [CrossRef] [PubMed]

34. Burglova, K.; Noureddine, A.; Hodacova, J.; Toquer, G.; Cattoen, X.; Wong Chi Man, M. A General Method for Preparing Bridged Organosilanes with Pendant Functional Groups and Functional Mesoporous Organosilicas. Chem. Eur. J. 2014, 20, 10371-10382. [CrossRef]

35. Boger, D.L.; Goldberg, J.; Andersson, C.-M. Solution Phase Combinatorial Synthesis of Biaryl Libraries Employing Heterogeneous Conditions for Catalysis and Isolation with Size Exclusion Chromatography for Purification. J. Org. Chem. 1999, 64, 2422-2427. [CrossRef]

36. Croissant, J.; Cattoen, X.; Wong Chi Man, M.; Gallud, A.; Raehm, L.; Trens, P.; Maynadier, M.; Durand, J.-O. Biodegradable Ethylene-Bis(Propyl)Disulfide-Based Periodic Mesoporous Organosilica Nanorods and Nanospheres for Efficient In-Vitro Drug Delivery. Adv. Mater. 2014, 26, 6174-6178. [CrossRef] 
37. Li, B.; Li, R.; Dorff, P.; McWilliams, J.C.; Guinn, R.M.; Guinness, S.M.; Han, L.; Wang, K.; Yu, S. Deprotection of N-Boc Groups under Continuous-Flow High-Temperature Conditions. J. Org. Chem. 2019, 84, 4846-4855. [CrossRef]

38. Feinle, A.; Flaig, S.; Puchberger, M.; Schubert, U.; Hüsing, N. Stable carboxylic acid derivatized alkoxy silanes. Chem. Commun. 2015, 51, 2339-2341. [CrossRef] 